Article

\title{
Targeting of Inhaled Therapeutics to the Small Airways: Nanoleucine Carrier Formulations
}

\author{
Danforth P. Miller ${ }^{1}$, Thomas E. Tarara ${ }^{1}$ and Jeffry G. Weers ${ }^{1, *}$ \\ 1 Respira Therapeutics, Inc.; NRangachari@respiratherapeutics.com \\ * Correspondence: jweers@cysteticmedicines.com; Tel.: 001-650-339-3832
}

\begin{abstract}
Current dry powder formulations for inhalation deposit a large fraction of their emitted dose in the upper respiratory tract where they contribute to off-target adverse effects and variability in lung delivery. The purpose of current study is to design a new formulation concept that more effectively targets inhaled dry powders to the large and small airways. The formulations are based on adhesive mixtures of drug nanoparticles and nanoleucine carrier particles prepared by spray drying of a co-suspension of leucine and drug particles from a nonsolvent. The physicochemical and aerosol properties of the resulting formulations are presented. The formulations achieve $93 \%$ lung delivery in the Alberta Idealized Throat model that is independent of inspiratory flow rate and relative humidity. Largely eliminating URT deposition with a particle size larger than solution pMDIs is expected to improve delivery to the large and small airways, while minimizing alveolar deposition and particle exhalation.
\end{abstract}

Keywords: respirable agglomerates; inhaled corticosteroids; ciclesonide; particle engineering; dry powder inhaler; extrafine; total lung dose; Alberta Idealized Throat; Idealized Child Throat

\section{Introduction}

The respiratory tract is divided into two principal regions, the upper respiratory tract (URT) comprising the mouth, larynx, and pharynx, and the lower respiratory tract (LRT) comprising the trachea and lungs. For therapeutics administered via oral inhalation, the LRT is generally the target. Unwanted deposition of particles in the URT may lead to local adverse events (e.g., throat irritation, cough, dysphonia, and opportunistic infections). If orally bioavailable, drug deposited in the URT may also contribute to systemic adverse events.

Regional deposition within the LRT may also be critical for effective drug delivery [1]. Traditionally, the LRT has been divided into two principal regions: (1) the conducting airways comprising the large airways, bronchioles and terminal bronchioles which extend from generation 0 to generation 15 , and (2) the respiratory zone comprising the respiratory bronchioles in generations 16-19 and the alveolar ducts and alveoli in generations 20-23. The conducting airways contain pseudostratified, ciliated airway epithelial cells that remove particles and pathogens by a process known as mucociliary clearance. As such, deposition in the conducting airways can be estimated using 24-h clearance studies with imaging techniques (e.g., gamma scintigraphy and single photon emission computed tomography). Insoluble particles that are not cleared on the mucociliary escalator within this time are assumed to be deposited in the respiratory zone (also referred to as peripheral deposition). Drug that is cleared over this time is deemed to be deposited in the conducting airways (also referred to as central deposition).

During the past decade, there has been increasing evidence that the 'small airways' (i.e., airways $<2 \mathrm{~mm}$ in internal diameter, comprising generations 8 to 19 in the respiratory tree) contribute substantially to the pathophysiology and clinical expression of asthma and chronic obstructive lung disease (COPD) [2-6]. The small airways span both the central and peripheral regions of the lungs. 
For particles to be deposited in the lung periphery, they must first bypass inertial impaction in the URT and large airways, after which they must sediment in the small airways or alveoli before being exhaled [1]. The Stokes number (Stk) defines the tendency that a particle will diverge from the airflow and deposit by inertial impaction in the respiratory tract:

$$
S t k=\frac{\rho_{p} d_{p}^{2} u}{18 \mu D} \sim \frac{d_{a}^{2} Q}{18 \mu D}
$$

where $d_{p}, \rho_{p}$, and $d_{a}$ are the particle diameter, density, and aerodynamic diameter, respectively, $u$ and $\mu$ are the linear velocity and dynamic viscosity of the carrier gas, and $D$ is a characteristic length scale equal to the diameter of the airspace. The volumetric flow rate, $Q$, is often used to approximate the linear velocity. The product $d_{a}^{2} Q$ is termed the 'impaction parameter'.

The terminal settling velocity for particles in the lung periphery, $v$, is also proportional to $d_{a}$, but is no longer dependent on $Q$ :

$$
v=\frac{\rho_{p} d_{p}^{2}}{18 \mu} g \sim \frac{d_{a}^{2}}{18 \mu} g
$$

Here, $g$ is the acceleration due to gravity.

Current marketed dry powder inhalers (DPIs) for the treatment of asthma and COPD comprise either adhesive mixtures of coarse lactose carrier particles (median diameter, $\mathrm{X}_{50}$ $=60-200 \mu \mathrm{m}$ ) and micronized drug particles (lactose blends, LB), or spheronized agglomerates $\left(\mathrm{X}_{50} \sim 100 \mu \mathrm{m}\right)$ of micronized drug $(\mathrm{SPH})$. These types of formulations exhibit bimodal particle size distributions, with the fine mode comprising free micronized drug particles, and the coarse mode comprising either agglomerated drug in SPH, or drug adhered to coarse carrier particles in LB. Unfortunately, dispersion of drug particles from the non-respirable agglomerates in these formulations is poor, with $50-90 \%$ of the emitted dose lost in the URT [7].

An empirical relationship between the impaction parameter and deposition in the URT of adults was first established by Stahlhofen et al. for monodisperse aerosols [8]. The experimental data are plotted in Fig. 1. The empirical fit to the data is given by:

$$
\text { URT Deposition }=\left[1-\left(4.17 \times 10^{-6}\left(d_{a}^{2} Q\right)^{1.7}+1\right)^{-1}\right] \times 100
$$

As expected, increases in $d_{a}^{2} Q$ lead to corresponding increases in URT deposition. The shaded area in Fig. 1a represents the range of $d_{a}^{2} Q$ values of current marketed products comprising SPH and LB formulations $\left(d_{a}^{2} Q \sim 1452\right.$ to $\left.5286 \mu \mathrm{m}^{2} \mathrm{~L} \mathrm{~min}^{-1}\right)$ [7]. This range of $d_{a}^{2} Q$ results in the $50-90 \%$ mean deposition in the URT observed with these products.

For $d_{a}^{2} Q$ values between about 1500 to $3000 \mu \mathrm{m}^{2} \mathrm{~L} \mathrm{~min}{ }^{-1}$ (i.e., the sweet spot for lactose blends and spheronized particles), URT deposition for individuals may vary anywhere between $5 \%$ and $90 \%$ depending on the anatomical features of their mouth and throat $[8,9]$. Along the sigmoidal deposition curve, the variability in URT deposition decreases as $d_{a}^{2} Q$ increases above $\sim 10,000 \mu \mathrm{m}^{2} \mathrm{~L} \mathrm{~min}^{-1}$ (i.e., in the limit where all particles deposit in the URT), or as $d_{a}^{2} Q$ decreases to $\sim 100 \mu \mathrm{m}^{2} \mathrm{~L} \mathrm{~min}^{-1}$ (i.e., in the limit where most particles bypass deposition in the URT) [8].

The high variability in lung delivery also shifts the clinical dose response curve to higher nominal doses. While this helps to ensure that most patients achieve a therapeutic dose, it also results in additional drug being available to contribute to off-target effects.

In vitro anatomical throat models have recently been developed that enable estimates of URT deposition and the total lung dose (TLD) in various ages of subjects (e.g., adults, 
pediatrics, and infants) [10-17]. These models have demonstrated good in vitro-in vivo correlations for URT deposition and TLD for various inhaled drug products, making them a valuable tool in formulation design [18-26].

The influence of the impaction parameter on regional deposition within the lungs is less clear. Regional deposition of monodisperse liquid droplets containing albuterol was assessed for mild asthmatics with gamma scintigraphy by Usmani et al. [27] (Fig. 1b). Consistent with Fig. 1a, URT deposition increased with increasing $d_{a}^{2} Q$. Significant increases in peripheral lung delivery, as indicated by the sum of peripheral lung deposition and the fraction of drug exhaled $(\mathrm{P}+\mathrm{EXH})$ was observed as $d_{a}^{2} Q$ approached $100 \mu \mathrm{m}^{2} \mathrm{~L}$ $\min ^{-1}$.
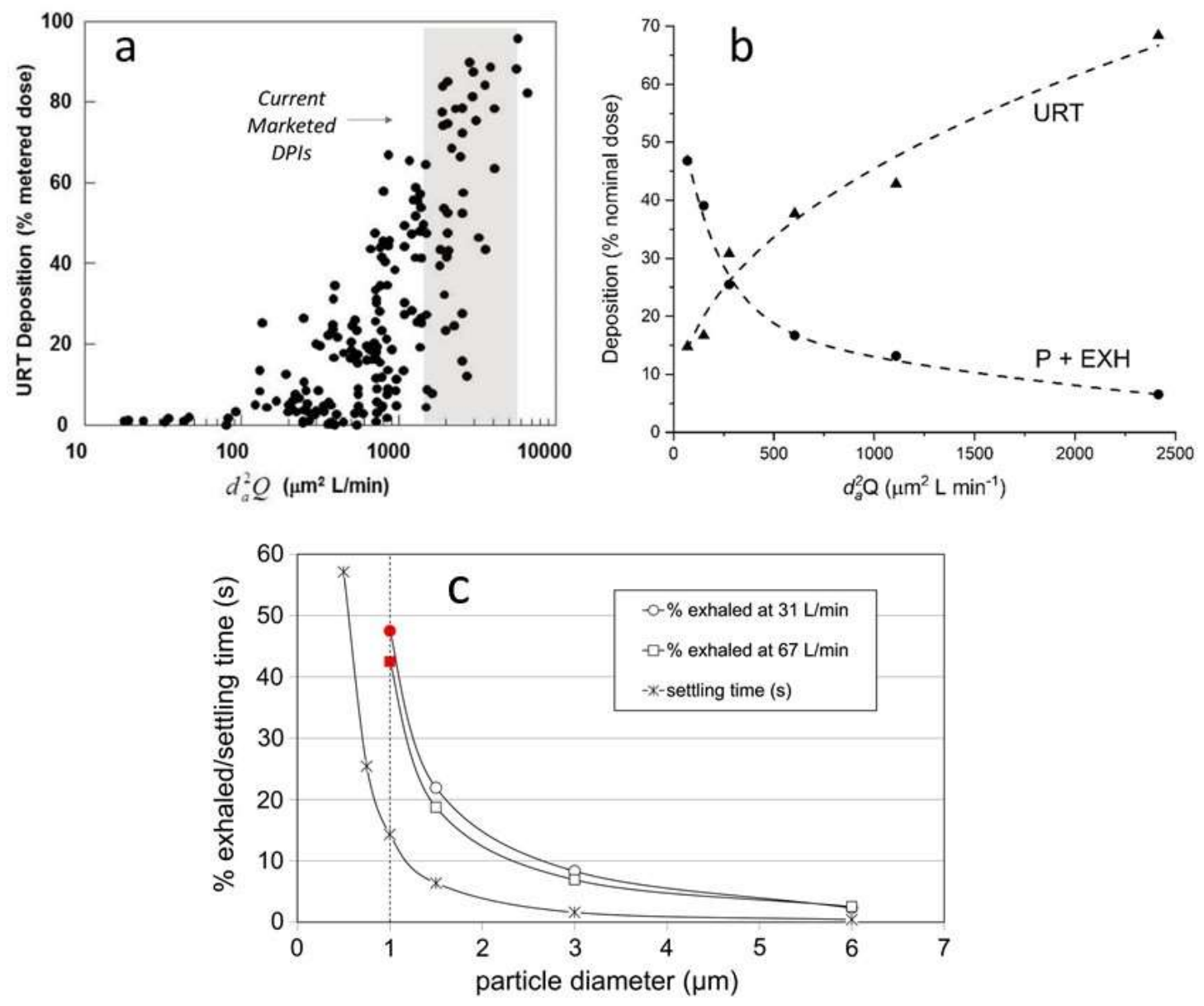

Fig. 1. Particle deposition and exhalation in adult subjects as a function of variations in the impaction parameter, $d_{a}^{2} Q$ and $d_{a}$ : (a) data for monodisperse liquid aerosols from Stahlhofen et al. [7,8]; (b) plot constructed from results of Usmani et al. for delivery of monodisperse particles of albuterol to adult subjects with mild asthma [27]; (c) comparison of the particle fraction exhaled and the time needed to sediment a distance $0.43 \mathrm{~mm}$ in a respiratory bronchiole at a stationary settling velocity. Both curves share the same ordinate. The figure is also constructed from results of Usmani et al. study [27] and extrapolated to $1 \mu \mathrm{m}$ particles [28].

Fig. 1c shows the impact of decreasing $d_{a}$ on the probability of particle exhalation according to equation 2 [28]. Note that subjects in this study did not perform a breath- 
hold following inhalation. For an extrafine particle with $d_{a} \sim 1.0 \mu \mathrm{m}$, the time for sedimentation within a $0.43 \mathrm{~mm}$ respiratory bronchiole is $\sim 15$ seconds. The sedimentation time decreases to less than 5 seconds for a particle with $d_{a} \sim 2.0 \mu \mathrm{m}$. Hence, the probability of achieving effective dose delivery to the peripheral regions of the lungs without particle exhalation increases for particles on the order of $2.0 \mu \mathrm{m}$. It also remains unclear what fraction of the peripheral dose is deposited in the respiratory bronchioles versus the alveoli. It is likely that the alveolar fraction increases with extrafine particles on the order of 1.0 $\mu \mathrm{m}$ compared to particles with a $d_{a} \sim 2.0 \mu \mathrm{m}$.

In previous studies we demonstrated how carrier-free formulations of spray-dried particles can effectively bypass URT deposition with just $2 \%$ to $5 \%$ extrathoracic deposition $[7,29]$. In the current manuscript we present results for a carrier-based formulation with a target $d_{a}$ and $d_{a}^{2} Q$ of $\sim 2.0 \mu \mathrm{m}$ and $\sim 100 \mu \mathrm{m}^{2} \mathrm{~L} \mathrm{~min}^{-1}$, respectively. As discussed, particles with these characteristics should largely bypass URT deposition with significant delivery to the small airways in the lungs. Although the utility of the technology is demonstrated in the context of the inhaled corticosteroid, ciclesonide, it can be applied to most therapeutics provided they are potent with a total lung dose less than $\sim 1 \mathrm{mg}$.

\section{Materials and Methods}

\subsection{Materials}

Ciclesonide (batch CS-17007(JM-01)-001) was obtained from Aarti Industries Ltd. (Maharashtra, India). Water (HiPerSolv Chromano grade), Tween 20, and leucine were obtained from VWR Life Sciences (Solon, Ohio). Glycerol and 2-propanol were obtained from Alfa Aesar (Ward Hill, MA), while trifluoroacetic acid, methanol, and ethanol were obtained from JT Baker (Radnor, PA). USP Perflubron (perfluorooctyl bromide, PFOB) was obtained from Atofina (Paris, France).

\subsubsection{Manufacture of Ciclesonide Powder for Inhalation (CPI)}

The strategy around the design of an adhesive mixture with $d_{a}^{2} Q \sim 100 \mu \mathrm{m}^{2} \mathrm{~L} \mathrm{~min}^{-1}$ is simple: eliminate the coarse fraction in the bimodal particle size distribution of conventional lactose blends. This may be achieved by developing a binary adhesive mixture of carrier and drug where drug-carrier and carrier-carrier agglomerates are respirable $\left(d_{a}<5 \mu \mathrm{m}\right)$. In such a circumstance there is no need to disperse the drug from the carrier to achieve effective aerosol delivery to the lungs.

The use of fine cohesive powders as carriers may seem counterintuitive given that lactose blends were developed to overcome the poor powder flow characteristics observed with fine, jet-milled drug particles sans carrier. However, the introduction of asperities in corrugated particles prepared by spray drying reduces interparticle cohesive forces sufficiently to enable: (1) accurate and precise filling of fine particles with drumbased filling machines, and (2) effective fluidization, emptying, and dispersion of powder agglomerates from passive DPIs [30-32].

Adhesive mixtures of extrafine ciclesonide particles and leucine carrier particles (ciclesonide powder for inhalation, CPI) were manufactured via a three-step manufacturing process (Fig. 2).

In step (a), fine leucine carrier particles were prepared by spray drying a $1.0 \% \mathrm{w} / \mathrm{v}$ solution of leucine in water. The solution was spray-dried on a Büchi B-191 spray dryer (Büchi, Flawil, Switzerland) with an inlet temperature of $110^{\circ} \mathrm{C}$, an outlet temperature of $65-70^{\circ} \mathrm{C}$, an aspirator setting of $100 \%$, an atomizer gas pressure of $70 \mathrm{psi}$, and a liquid feed rate of $5.0 \mathrm{~mL} / \mathrm{min}$. A custom-built (Adams and Chittenden, Berkeley, CA) glass cyclone $\left(1.75^{\prime \prime}\right)$ was used with a $1.25^{\prime \prime}$ diameter $x 8^{\prime \prime}$ long collector. 
In step (b), a concentrated solution of ciclesonide in isopropanol was prepared at about $50 \%$ of its solubility $(112 \mathrm{mg} / \mathrm{mL}$ ). Using an infusion pump (Harvard Apparatus, PHD2000) coupled with a precision $1.0 \mathrm{~mL}$ gas-tight syringe (Hamilton 81301 ), the ciclesonide solution was then added dropwise to a well-stirred large volume of perflubron (PFOB) containing a $3.5 \% \mathrm{w} / \mathrm{v}$ of a milky suspension of the leucine particles from step (a). The sudden change in solvent composition upon mixing of the alcohol and perflubron results in flash precipitation of extrafine ciclesonide particles. Although the size of the ciclesonide nanoparticles was not determined in the present study, previous studies exploring flash precipitation of inhaled corticosteroids in perflubron found a mean particle diameter of about $60 \mathrm{~nm}$ [33]. To achieve a target composition of $1 \%$ ciclesonide / 99\% leucine, only $0.15 \mathrm{~mL}$ of ciclesonide solution needed to be added to approximately $44 \mathrm{~mL}$ of perflubron. Thus, the combined solvent (perflubron and isopropanol) was predominantly perflubron $(\approx 99.7 \% \mathrm{v} / \mathrm{v})$. The very low solubility of ciclesonide in perflubron limits the potential for coarsening by molecular diffusion (Ostwald ripening) $[34,35]$.

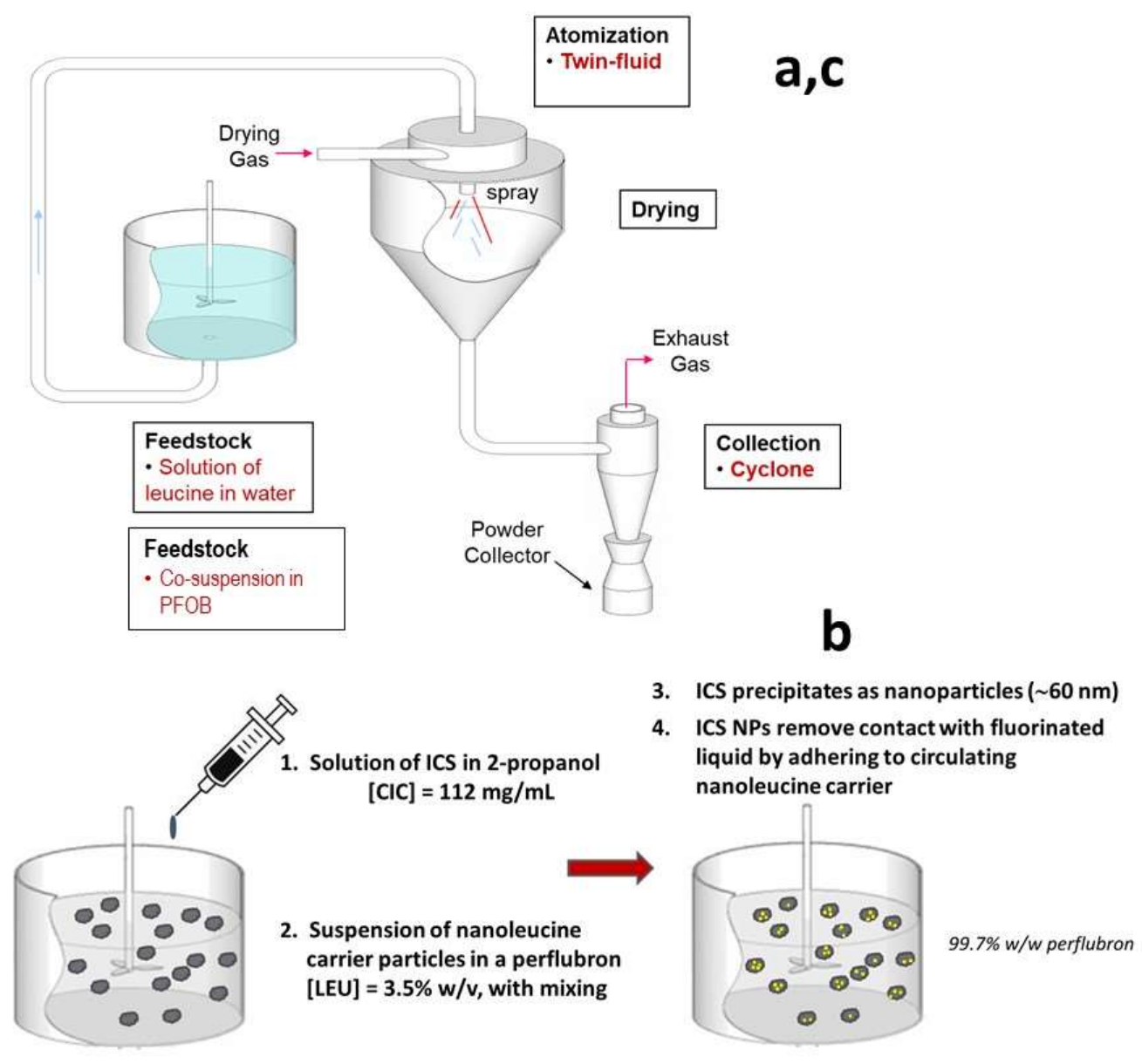

Fig. 2: Process for the manufacture of adhesive mixtures of nanoleucine carrier particles and extrafine ciclesonide particles

The leucine suspension in perflubron was mixed with a stir bar during alcohol addition. This process enabled uniform mixing of the drug and carrier particles, an outcome 
difficult or nearly impossible to achieve when mixing dry powders of this size with conventional low-shear and high-shear mixers [36,37]. Given their small size and desire to minimize interfacial contact with the fluorinated liquid, it is likely that the extrafine ciclesonide particles are rapidly adsorbed onto the carrier particles to form a co-suspension. The rapid association of drug and carrier to form a co-suspension in a fluorinated liquid was observed previously for micronized drug and PulmoSphere placebo particles in hydrofluoroalkane propellants [38].

In step (c), the nonsolvent is removed to form a dry powder. For this step, the Büchi B-191 spray dryer was utilized with the same hardware configuration as detailed above. The spray-drying conditions included an inlet temperature of $110^{\circ} \mathrm{C}$, an outlet temperature of 75 to $80^{\circ} \mathrm{C}$, an aspirator setting of $100 \%$, an atomizer gas pressure of $70 \mathrm{psi}$, and a liquid feed rate of $5.0 \mathrm{~mL} / \mathrm{min}$. The resulting dry powder comprises an adhesive mixture of extrafine ciclesonide particles adhered to the leucine carrier particles.

\subsubsection{Capsule Filling of CPI}

Size 3 hydroxypropylmethylcellulose (HPMC) clear capsules (Quali-V) were supplied by Qualicaps (Indianapolis, IN). The capsules were hand-filled with CPI to achieve a fill mass of $\sim 6 \mathrm{mg}$. For the target $1 \% \mathrm{w} / \mathrm{w}$ ciclesonide content, this corresponds to a nominal dose of $\sim 60 \mu \mathrm{g}$.

\subsection{Methods}

\subsubsection{Primary Particle Size Distribution}

Primary particle size distributions of the fine leucine carrier particles $(<5 \mu \mathrm{m})$ and their adhesive mixtures with extrafine ciclesonide particles $(<2 \mu \mathrm{m})$ were determined via laser diffraction (Sympatec GmbH, Clausthal-Zellerfeld, Germany) at a high dispersing pressure. The Sympatec H3296 unit was equipped with an R2 lens, an Aspiros micro dosing unit, and a RODOS/M dry powder-dispersing unit. Approximately $2-5 \mathrm{mg}$ powder was filled into tubes, sealed and fed at a rate of $5 \mathrm{~mm} / \mathrm{s}$ into the RODOS operated with 4 bar dispersion pressure and $65 \mathrm{mbar}$ vacuum. Powders were introduced at an optical concentration of approximately $1 \%$ to $5 \%$ and data were collected over a measurement duration of up to 15 seconds. Particle size distributions were calculated by the instrument software using a Fraünhofer model. The particle size distributions are reported at three cut points in the distribution (i.e., $X_{10}, X_{50}$, and $X_{90}$ ), which represent the volume-weighted size cutoffs for $10 \%, 50 \%$, and $90 \%$ of the particles in the distribution.

\subsubsection{Tapped Density}

Tapped densities were determined using a cylindrical cavity of known volume (0.593 $\mathrm{cm}^{3}$ ). Powder was filled into this sample holder using a microspatula. The sample cell was then gently tapped on a countertop. As the sample volume decreased, more powder was added to the cell. The tapping and addition of powder steps were repeated until the cavity was filled, and the powder bed no longer consolidated with further tapping. The tapped density is defined as the mass of the tapped bed of powder divided by the volume of the cavity.

\subsubsection{X-Ray Powder Diffraction (XRPD)}

X-ray powder diffraction patterns of selected powders were measured with a Rigaku Miniflex Model 600 diffraction system equipped with a D/Tex solid state 'strip' detector (Rigaku, Tokyo, Japan). Each sample was prepared by packing bulk powder into a sample holder with a zero-background silicon insert. Samples were scanned from 3 to $35^{\circ} 2 \theta$ at a scan rate of $1^{\circ} 2 \theta / \mathrm{min}$, using a Cu radiation source with a wavelength of $1.54 \AA$, operated at $40 \mathrm{kV}$ and $15 \mathrm{~mA}$. During measurement, samples were rotated at $80 \mathrm{rpm}$. 


\subsubsection{Dynamic Vapor Sorption (DVS)}

The moisture sorption isotherm of CPI was measured at $25^{\circ} \mathrm{C}$ using a dynamic vapor sorption (DVS) instrument made by Surface Measurement Systems, UK. This instrument gravimetrically measures uptake and loss of water vapor by a material. The DVS system is equipped with a recording microbalance with a resolution of $\pm 0.1 \mu \mathrm{g}$ and a daily drift of approximately $\pm 1 \mu \mathrm{g}$. In the first step of the experimental run, the sample was dried at $25^{\circ} \mathrm{C}$ and $0 \% \mathrm{RH}$ for at least 600 minutes to bring the sample to a constant mass. Then, the instrument was programmed from 0 to $2 \% \mathrm{RH}$, to $5 \% \mathrm{RH}$, and then $\mathrm{RH}$ was increased in steps of $5 \%$ RH to $90 \% \mathrm{RH}$ and decreased in steps of $5 \% \mathrm{RH}$ from $90 \%$ to $0 \% \mathrm{RH}$. An equilibration criterion of $\mathrm{dm} / \mathrm{dt}=0.005 \% / \mathrm{min}$ was chosen for the system to achieve at each $\mathrm{RH}$ step before automatically proceeding to the next RH step. Sample masses between 10 and $15 \mathrm{mg}$ were used in this study.

\subsubsection{Ciclesonide determination by RP-HPLC with UV detection}

Quantitation of Ciclesonide was done by reversed phase high performance liquid chromatography (RP-HPLC) with UV detection. An Agilent 1260 Infinity Series module HPLC system equipped with a UV detector (Agilent Technologies, Santa Clara, CA, USA) was used. Separation was achieved with an Agilent InfinityLab Poroshell 120 EC-C18, 3.0 x $150 \mathrm{~mm}, 2.7 \mu \mathrm{m}$ column (P/N 693975-302) maintained at $40^{\circ} \mathrm{C}$ and gradient separation using water:trifluoroacetic acid $(0.025 \% \mathrm{v} / \mathrm{v})$ and acetonitrile:trifluoroacetic acid $(0.025 \%$ $\mathrm{v} / \mathrm{v}$ ) operated at $0.6 \mathrm{~mL} / \mathrm{min}$. The autosampler was maintained at $2-8^{\circ} \mathrm{C}$ and a $40 \mu \mathrm{L}$ injection volume was used. Ciclesonide detection was performed at a wavelength of $242 \pm 2$ $\mathrm{nm}$. Quantitation was performed by comparison to an external standard. Method linearity was established across a quantitation range from 0.08 to $200 \mu \mathrm{g} / \mathrm{mL}$.

\subsubsection{Assay and Blend Uniformity}

Assay testing was performed by weighing approximately $20 \mathrm{mg}$ of formulated bulk powder onto a tared weighing paper. The weighed material was recorded and analytically transferred into a $25 \mathrm{~mL}$ volumetric flask following USP $<1251>$ Method 3. The sample diluent (water/acetonitrile, 50/50 v/v) was used to rinse the residual materials into the flask. To evaluate assay/blend uniformity, three independent samples were weighed as described above. The samples represented different spatial locations from the container. The target nominal assay value was $10 \mu \mathrm{g}$ ciclesonide/mg powder.

\subsubsection{Emitted Dose}

The emitted dose (ED) represents the percentage of the nominal ciclesonide dose in the capsule that is discharged from the dry powder inhaler following device actuation. ED measurements were determined in accordance with USP <601 > using a model 8601A Dose Unit Sampling Apparatus, DUSA (Copley Scientific Limited, Nottingham, UK). For ED measurements, a filled capsule ( $6 \mathrm{mg}$ fill mass; target $60 \mu \mathrm{g}$ ciclesonide) was loaded into the AOS DPI inhaler and the capsule was pierced. The AOS DPI was then inserted into an aerosol mouthpiece adapter. A Copley model TPK2001 critical flow controller, and Copley model HCP vacuum pump drew air at a flow rate of $\sim 27.7 \mathrm{~L} \mathrm{~min}^{-1}$ (2 $\mathrm{kPa}$ pressure drop) for a total volume of $2 \mathrm{~L}$ through the inhaler. Powder was emptied from the device into the DUSA equipped with a $47 \mathrm{~mm} \mathrm{~A}$ /E type glass fiber $1 \mu \mathrm{m}$ filter (Pall Corp., Port Washington, N.Y., USA). The DUSA tube and filter were then extracted using $25 \mathrm{~mL}$ of sample diluent (water/acetonitrile, $50 / 50 \mathrm{v} / \mathrm{v}$ ). The extract was then filtered through a 25 $\mathrm{mm}, 0.2 \mu \mathrm{m}$ PTFE syringe filter. The mass balance of the ED test was assessed by also quantitating the residual ciclesonide in the actuated capsule and that deposited in the AOS DPI. The capsules and device were extracted using $2 \mathrm{~mL}$ and $5 \mathrm{~mL}$ of sample diluent, respectively. Each sample was quantitated for ciclesonide by RP-HPLC as detailed above and reported in terms of the percentage of the total recovered dose.

2.2.8. Aerodynamic Particle Size Distribution (APSD) 
Aerodynamic particle size distributions (APSD) were determined with a Next Generation Impactor (NGI) equipped with a USP induction port (MSP Corp. Minneapolis, MN, USA). Tests were conducted in accordance with USP <601> Aerosols 'Aerodynamic Size Distribution, Apparatus 6 for Dry Powder Inhalers' and Ph. Eur. 2.9.18 ‘Preparations for Inhalation; Aerodynamic Assessment of Fine Particles; Apparatus E’. To prevent reentrainment/bounce of particles within the NGI, the impactor stages were coated with a solution comprising $50 \% \mathrm{v} / \mathrm{v}$ ethanol, $25 \% \mathrm{v} / \mathrm{v}$ glycerol, $22.5 \% \mathrm{v} / \mathrm{v}$ water, and $2.5 \% \mathrm{v} / \mathrm{v}$ Tween 20. For stage 1 in the NGI, $2 \mathrm{~mL}$ of coating solution was used, $1.5 \mathrm{~mL}$ on stages 3 to $5,1 \mathrm{~mL}$ on stages 2,6 , and 7 , and $0.5 \mathrm{~mL}$ on the MOC (micro-orifice collector). APSD testing was conducted with the $\mathrm{AOS}^{\circledR} \mathrm{DPI}$ [39] at a pressure drop of $4 \mathrm{kPa}$, and an inhaled volume of $4 \mathrm{~L}$. The $4 \mathrm{kPa}$ pressure drop corresponds to a flow rate of $\sim 40 \mathrm{~L} \mathrm{~min}^{-1}$ for the high-resistance AOS DPI ( $\left.\mathrm{R} \sim 0.051 \mathrm{kPa}^{0.5} \mathrm{~L}^{-1} \mathrm{~min}\right)$. Quantitation of ciclesonide on each stage was performed by RP-HPLC as described above. Powder deposited within the induction port (IP) was extracted using $10 \mathrm{~mL}$ of sample diluent, NGI stages 1, 2 and MOC were extracted with $5 \mathrm{~mL}$, and stages 2 through 7 were extracted using $10 \mathrm{~mL}$ of sample diluent. The fine particle fraction $\left(\mathrm{FPF}_{<5 \mu \mathrm{m}}\right)$ is reported as the percentage of active ingredient in the emitted dose with an aerodynamic size less than $5 \mu \mathrm{m}$.

\subsubsection{Mass Median Impaction Parameter (MMIP) and Stage Groupings}

The mass median impaction parameter (MMIP) utilizes the impaction parameter cutoffs for the stages in an NGI as opposed to their size cutoffs [40]. Given that deposition within the respiratory tract depends on both the size and inhaled flow rate, MMIP provides a better correlate to regional deposition within the respiratory tract than does MMAD [40,41].

Fine particle fractions based on stage groupings (i.e., impaction parameters) are also reported here. The stage groupings include the 'large particle fraction' comprising deposition on the USP induction port and stages 1 and 2 (mean $\left.d_{a}^{2} Q>1176 \mu \mathrm{m}^{2} \mathrm{~L} \mathrm{~min}^{-1}\right)$. When using the induction port, deposition on these stages contributes to extrathoracic deposition in the URT. The 'airways fraction' refers to deposition on stage 3 through stage 5 (1176 $\left.\geq d_{a}^{2} Q \geq 56 \mu \mathrm{m}^{2} \mathrm{~L} \mathrm{~min}^{-1}\right)$, while the 'very fine particle fraction' refers to deposition on stages 6 to $\mathrm{MOC}\left(d_{a}^{2} Q<56 \mu \mathrm{m}^{2} \mathrm{~L} \mathrm{~min}^{-1}\right)$. The extrafine fraction is thought to be largely associated with alveolar deposition, while deposition on stages 4 and 5 may be associated with small airways delivery. As pointed out by Dolovich et al. [42], "cascade impactors are not lung simulators", and deposition of particles is far more complex than what a simple impactor can discern. Nonetheless, we are looking for gross differences in the APSD between various types of formulations with the hope of providing high level guidance on how these changes may impact deposition in the respiratory tract for an average subject. Ultimately, these hypotheses must be tested in vivo in patients in clinical studies. By using stage groupings as opposed to size cutoffs, we believe we have eliminated one major source of error in using cascade impactors for estimating regional lung deposition.

\subsubsection{Total Lung Dose}

When a patient inhales through a passive DPI, the inhalation airflow generates the aerodynamic forces required to fluidize and deagglomerate powders into aerosols. These processes are complex to model, being highly dependent on formulation and device design, and sensitive to inhalation maneuver [43]. As such, it is generally easier to predict URT deposition in vitro by performing experiments using anatomical throat models.

The Alberta Idealized Throat (AIT) model represents an idealized version of the URT of an average adult subject $[10,11]$. The AIT geometry contains simplified analogues of anatomical features that heavily influence the transport and deposition of aerosols in the URT. The Idealized Child Throat (ICT) mimics the average deposition during oral inhalation among children 6-14 years of age $[12,13]$. Based on CT scans it appears that the main 
geometrical features of child and adult airways are similar. Hence, the ICT was simply adapted from the AIT with a scale factor of 0.62 [12,13]. Good in vitro/in vivo correlations have been established for pharmaceutical aerosols with these idealized and other anatomical throat models [14-26].

Fig. 3a shows plots of deposition in children (ICT model) and adults (Stahlhofen data from Fig. 1a) as a function of $d_{a}^{2} Q$. As the characteristic dimension of the airways decreases in younger subjects, equivalent URT deposition is shifted to smaller $d_{a}^{2} Q$ values. Hence, finer aerosols are needed to bypass URT deposition in children. The curve fit for URT deposition in the average child in the ICT model is presented in equation 4 [12].

$$
\text { URT deposition }(I C T)=\left[1-1 /\left(0.0001 d_{a}^{2} Q+1\right)\right] \times 6
$$

Fig $3 \mathrm{~b}$ plots the data from Fig. $3 \mathrm{a}$ in a different fashion, showing the combinations of $Q$ and $d_{a}$ needed to achieve the target $d_{a}^{2} Q$ value required for $10 \%$ URT deposition. For a 39.2 $\mathrm{L} \mathrm{min}^{-1}$ flow rate $\left(4 \mathrm{kPa}\right.$ pressure drop with the AOS DPI), the required $d_{a}$ is about $1.2 \mu \mathrm{m}$ in the ICT and $3.1 \mu \mathrm{m}$ in the AIT.
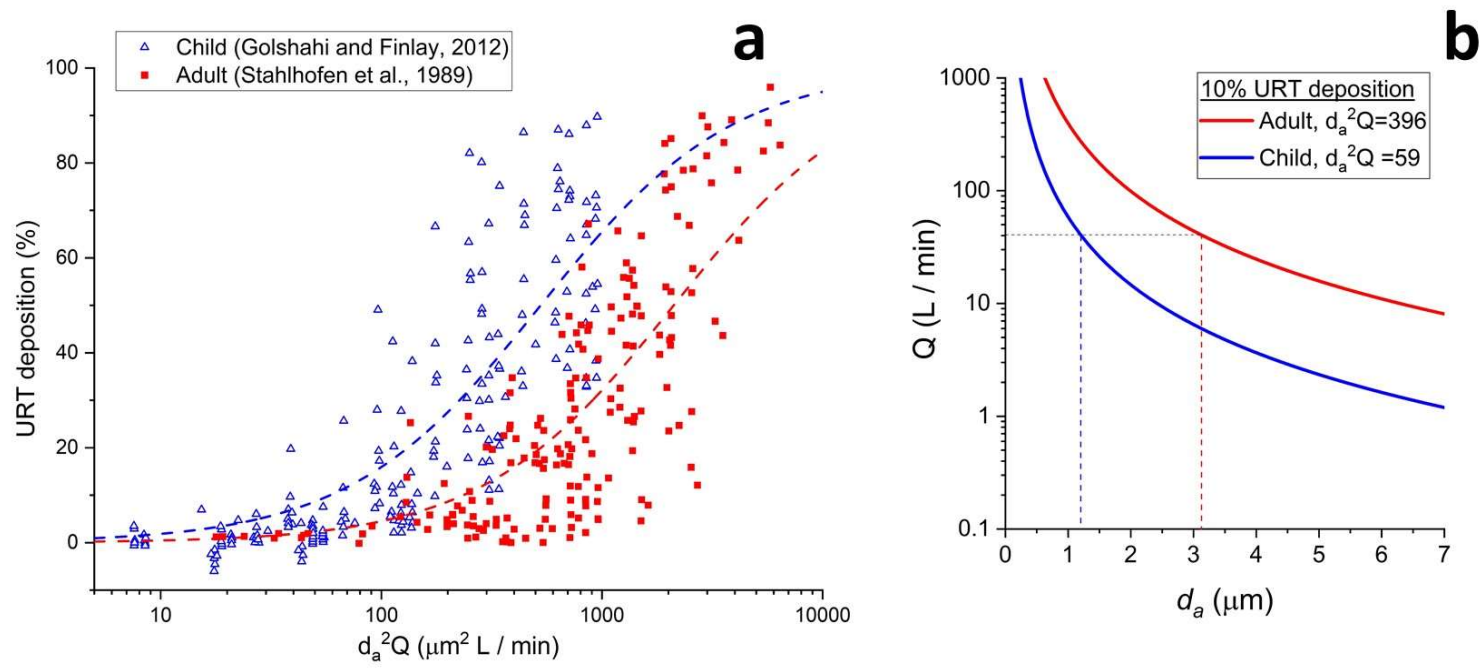

Fig. 3: In vitro anatomical throat models. (a) plot of URT deposition versus impaction parameter for child, and adult $[8,12]$. (b) Combination of flow rate and aerodynamic diameter that provide $10 \%$ URT deposition in adult and child throat models.

Stainless steel versions of the AIT and ICT throats were obtained from MSP Corporation. For TLD measurements, the AOS DPI was coupled to the inlet of the throat using a custom mouthpiece adaptor, and the downstream end of the AIT was mounted to the filter housing stage of a Fast-Screening Impactor, FSI (MSP Corporation). The TLD that bypassed the throat was collected downstream on a $76 \mathrm{~mm}$ diameter A/E type glass fiber $1 \mu \mathrm{m}$ filter (Pall Corp., Port Washington, NY). To prevent particle resuspension, the interior surfaces of the throats were coated with $15 \mathrm{~mL}$ of a solution comprising $50 \% \mathrm{v} / \mathrm{v}$ methanol and $50 \% \mathrm{v} / \mathrm{v}$ Tween 20 . The coating solution was allowed to wet the internal walls of the AIT using a rocking or rotary motion to tilt the AIT from side to side. Excess coating solution was allowed to drain for 5 min before use.

During the TLD measurement, a filled CPI capsule was first loaded into the AOS DPI and pierced. A Copley model TPK2001 critical flow controller and Copley model HCP5 vacuum pump was activated to draw air at the desired pressure drop through the inhaler for a total volume of $2 \mathrm{~L}$. The filter was removed from the FSI filter housing and placed in 
a liquid-tight plastic bag. The drug on the filter was then extracted using $20 \mathrm{~mL}$ of sample diluent (water/acetonitrile, 50/50 v/v). Each sample was quantitated for ciclesonide by RPHPLC as detailed above and reported in terms of percentage of the total recovered dose relative to the average emitted dose. The mass balance of the test was assessed by quantitating the residual ciclesonide remaining in the actuated capsule and deposited in the AOS DPI. The capsules were extracted using $2 \mathrm{~mL}$ of sample diluent and $5 \mathrm{~mL}$ was used for the inhaler.

All ED, APSD, and TLD determinations were conducted under ambient laboratory conditions ( 20-40\% RH). Environmental robustness at high humidity was assessed by comparing the TLD measured with the ICT model at ambient conditions with TLD measured conducted in an environmental chamber (Barnstead International, Dubuque, IA, Model EC12560) at $25^{\circ} \mathrm{C} / 75 \% \mathrm{RH}$.

\section{Results}

\subsection{Nanoleucine carrier particles}

The leucine carrier particles utilized in the manufacture of the CPI batch described herein had a median geometric diameter $\left(x_{50}\right)$ of $2.21 \mu \mathrm{m}$ and a tapped density $\left(\rho_{\text {tapped }}\right)$ of $0.038 \mathrm{~g} / \mathrm{cm}^{3}$. It should be noted that these carrier particles are 25-100 times smaller than traditional lactose carrier particles. The geometric size and tapped density can be used to estimate the median aerodynamic diameter of the primary leucine carrier particles, $D_{a}$, using equation $5[7,29]$ :

$$
D_{a}=x_{50} \sqrt{\rho_{\text {tapped }}}
$$

For this batch, $D_{a}$ is equal to $430 \mathrm{~nm}$. Thus, from an aerodynamic perspective, the carrier particles can be described as 'nanoleucine carrier particles'. Previous studies with spray-dried carrier-free formulations of proteins have demonstrated that for $D_{a}$ values between $300 \mathrm{~nm}$ and $700 \mathrm{~nm}$, the agglomerates in the dry powder aerosol had an MMAD of about 1.8-2.0 $\mu \mathrm{m}, d_{a}^{2} Q$ of about $105-135 \mu \mathrm{m}^{2} \mathrm{~L} \mathrm{~min}^{-1}$, and URT deposition in the AIT model between 2-5\% [7]. Hence, the primary nanoleucine carrier particles and their 'respirable agglomerates' with other carrier particles are expected to be able to effectively bypass URT deposition.

\subsection{Physicochemical Properties of Ciclesonide Powder for Inhalation}

The physicochemical properties observed for a selected batch of CPI containing $1.0 \%$ $\mathrm{w} / \mathrm{w}$ ciclesonide are detailed in Table 1 . Additional batches with higher drug loadings (5, 10 and $20 \% \mathrm{w} / \mathrm{w}$ ) were used for assessment of the physical form of the drug substance by XRPD. 
Table 1: Properties of ciclesonide powder for inhalation

\begin{tabular}{lcc}
\hline \multicolumn{1}{c}{ Metric } & Method & Mean \pm SD \\
\hline Ciclesonide assay $(\mu \mathrm{g} / \mathrm{mg})$ & RP-HPLC & $9.6 \pm 0.1$ \\
Geometric size $\quad X_{10}(\mu \mathrm{m})$ & Laser diffraction & $0.79 \pm 0.01$ \\
$X_{50}(\mu \mathrm{m})$ & Laser diffraction & $1.70 \pm 0.02$ \\
$X_{90}(\mu \mathrm{m})$ & Laser diffraction & $3.16 \pm 0.05$ \\
Tapped density $\left(\mathrm{g} / \mathrm{cm}^{3}\right)$ & Tapped density & $0.047 \pm 0.001$ \\
$D_{a}(\mathrm{~nm})$ & Calculated & 370 \\
Water content $(\% \mathrm{w} / \mathrm{w})$ & DVS & $<0.3(90 \% \mathrm{RH})$ \\
ICS physical form & XRPD & Crystalline \\
Leucine physical form & XRPD & Crystalline \\
\hline
\end{tabular}

\subsection{CPI Particle Size Distribution}

Given the low drug content $(\sim 1.0 \% \mathrm{w} / \mathrm{w})$ and small size of the extrafine drug particles, the geometric size and tapped density of the adhesive mixture of drug and carrier is largely controlled by the size of the leucine carrier particles. Indeed, the $X_{50}(1.70 \mu \mathrm{m})$, $\boldsymbol{\rho}_{\text {tapped }}\left(0.047 \mathrm{~g} / \mathrm{cm}^{3}\right)$ and $D_{a}(370 \mathrm{~nm})$ values in the formulated CPI drug product are all comparable to the values observed for the nanoleucine carrier particles detailed above. The low $D_{a}$ value suggests that both drug-carrier and carrier-carrier agglomerates are likely to be respirable. This is further supported by the low $X_{90}$ value of just $3.16 \mu \mathrm{m}$.

\subsection{Drug Content and Blend Uniformity}

One of the challenges with the development of dry powder blends of fine carrier particles and extrafine drug particles is the large increases in interparticle cohesive forces relative to gravitational forces that occur with decreases in particle size [32,44]. This results in poor powder flow properties as assessed by metrics such as the Hausner ratio or Carr's index. This further leads to challenges in obtaining uniform blends with traditional powder mixing processes, such as low-shear and high-shear mixing. Whereas coefficients of variation in blend uniformity are less than $2 \%$ for conventional lactose blends, they can balloon to $>30 \%$ for mixtures comprising fine carrier particles [36]. In contrast, the manufacturing process used for CPI achieves uniform mixing of the fine and extrafine particles by creating stable suspensions of the drug and carrier particles in a liquid that is a nonsolvent for the two materials. Mixing of these suspensions with low-shear mixers (e.g., overhead mixers) leads to excellent uniformity in drug content with an RSD of just $1.04 \pm 0.01$ $\% \mathrm{w} / \mathrm{w}$ throughout the batch.

The unique blending process where the drug particles are created in a sea of carrier particles also limits the potential for development of drug-drug agglomerates, as is often observed with lactose blends. Free drug particles present in lactose blends may adhere to the walls of the receptacle (e.g., capsule or blister), or segregate from the carrier particles on storage [45]. This can be especially problematic for ultralow doses ( 20 $\mu \mathrm{g}$ or less), where any losses in uniformity can adversely affect dose delivery.

The cohesive forces between drug and carrier in CPI are likely to exceed the dispersion forces achievable with DPIs. Hence, the drug is expected to remain adhered to the carrier during the inhalation process. The strong adhesive force between drug and carrier is comparable to or stronger than the adhesive forces observed in co-suspension formulations in pressurized metered dose inhalers [38]. There, the energy generated by rapid expansion of the propellant during actuation and passage through a small orifice in the actuator is insufficient to disperse micronized drug from the small porous PulmoSphere ${ }^{\mathrm{TM}}$ (re-branded Aerosphere ${ }^{\circledR}$ ) carrier particles [38]. Given the small $D_{a}$ of the carrier 
particles with adsorbed drug, there is no need for the drug to be dispersed from the carrier to achieve effective lung delivery of CPI.

\subsection{Crystallinity}

X-ray powder diffraction (XRPD) experiments confirm that both the drug and carrier in the CPI drug product are highly crystalline (Fig. 4). This is illustrated for ciclesonide by a comparison of the $X$-ray powder patterns of precipitated ciclesonide with that of the raw material (e.g., unprocessed starting material) (Fig. 4a). The positions of the peaks indicate that the precipitated material is the same physical form (polymorph) as the as-received ciclesonide drug substance (e.g., see the pronounced peak at $6.7^{\circ} 2 \theta$ ). This crystalline polymorph of ciclesonide has been previously reported by Feth et al. [46]. These data also demonstrate the highly crystalline nature of the precipitated ciclesonide, as indicated by the lack of an amorphous background ('halo').

For the $1 \% \mathrm{w} / \mathrm{w}$ blend, the concentration of ciclesonide is near the limit of detection for the (benchtop) X-ray diffractometer used. As expected, the diffracted intensity of the ciclesonide peaks increases with drug loading. Fig. $4 \mathrm{~b}$ shows an overlay of the X-ray powder diffraction patterns of CPI powders comprising 1, 5, 10, and 20\% w/w ciclesonide. The $X$-ray powder diffraction patterns for different concentrations shows that the ciclesonide in the blends is crystalline, as indicated by the peak at $6.7^{\circ} 2 \theta$, which could be detected for blends with a ciclesonide concentration $\geq 5 \% \mathrm{w} / \mathrm{w}$. Upon enlargement of the powder pattern (not shown), weak diffraction peaks can be observed for the peaks at $14.9^{\circ} 2 \theta$ to $15.9^{\circ} 2 \theta$ of the $1 \% \mathrm{w} / \mathrm{w}$ ciclesonide powder. A qualitative assessment of the powder patterns in the blends indicates the highly crystalline nature of the blend formulation, as indicated by the lack of an amorphous background ('halo'). However, small amounts of amorphous material are difficult to detect via changes in the broad, diffuse background. A means to detect amorphous ciclesonide is to expose the sample to elevated relative humidity $(\mathrm{RH})$ and then determine if increases in the intensity of diffraction peaks are present. The 5\% ciclesonide/leucine blend was exposed to $75 \%$ RH for about 20 hours, an RH sufficiently high to depress the glass transition temperature $\left(\mathrm{T}_{\mathrm{g}}\right)$ of (any) amorphous ciclesonide and induce recrystallization. As shown in Fig. 4c, the XRPD patterns before and after exposure did not change. This indicates that, within the limit of detection of the method, the ciclesonide/leucine blend contains no amorphous ciclesonide.

A sharp diffraction peak is also observed for leucine at about $5.7^{\circ} 2 \theta$ indicating the crystalline nature of the leucine carrier particles [47]. The crystallinity of the carrier particles is an important aspect of the design of such formulations. Highly crystalline materials tend to be non-hygroscopic, taking up very little water even at elevated relative humidity conditions. A highly crystalline formulation comprising hydrophobic materials is expected to provide improved environmental robustness in aerosol performance relative to formulations comprising amorphous or even hydrophobic phospholipid carrier particles. Indeed, the crystallinity of the CPI drug product is further illustrated by the low moisture sorption of the nanoleucine blend $(<0.2 \%)$ at $90 \% \mathrm{RH}$. 


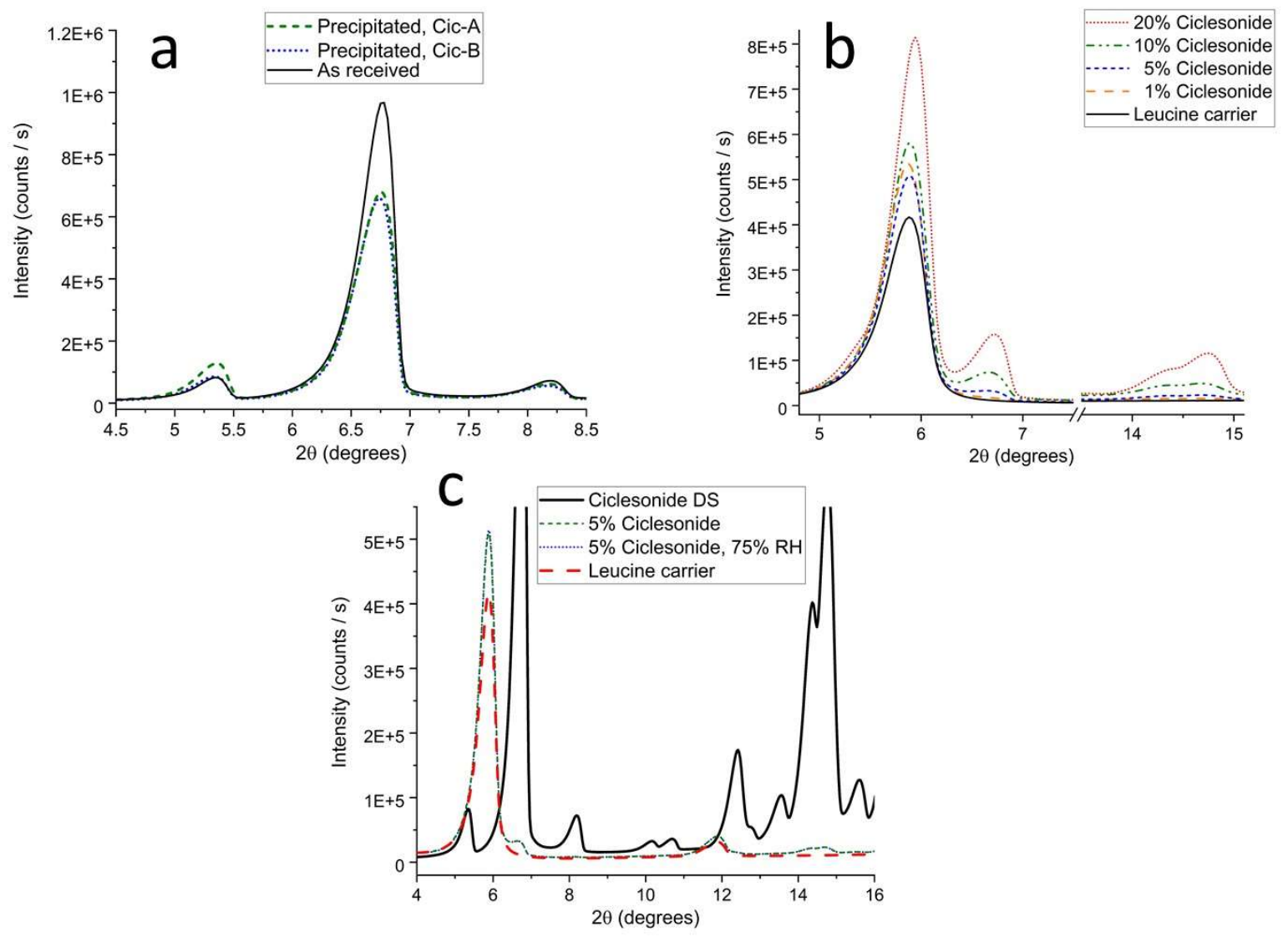

Fig. 4: X-ray powder diffraction patterns for ciclesonide and leucine. (a) comparison of the diffraction patterns for the as received drug substance with two batches of particles prepared by flash nanoprecipitation (Cic-A, Cic-B); (b) comparison of the diffraction patterns at 1, 5, 10, and 20\% $\mathrm{w} / \mathrm{w}$ ciclesonide with the leucine carrier; (c) comparison of the diffraction patterns observed for a $5 \% \mathrm{w} / \mathrm{w}$ CPI drug product before and after exposure to $75 \% \mathrm{RH}$, with the patterns observed for the drug substance and leucine excipient.

Fig. 5 compares the moisture sorption isotherms $\left(25^{\circ} \mathrm{C}\right)$ of $\mathrm{CPI}$ and spray-dried 'benchmark' PulmoSphere carrier particles comprising a 2:1 molar ratio of distearoylphosphatidylcholine (DSPC) to $\mathrm{CaCl}_{2}$. Owing to the unique phase behavior of the amphiphilic long-chain phospholipid, the PulmoSphere placebo is considerably more hygroscopic. Indeed, at any $\mathrm{RH}$, the DSPC: $\mathrm{CaCl}_{2}$ placebo is between 30 and 80 times more hygroscopic than the ciclesonide/leucine blend. Hence, the nanoleucine carriers are expected to provide more environmentally robust formulations than the PulmoSphere carriers studied previously $[36,37,48,49]$. Nanoleucine carrier particles may also provide improved environmental robustness for co-suspensions in pMDIs, provided they remain insoluble in the propellant. 


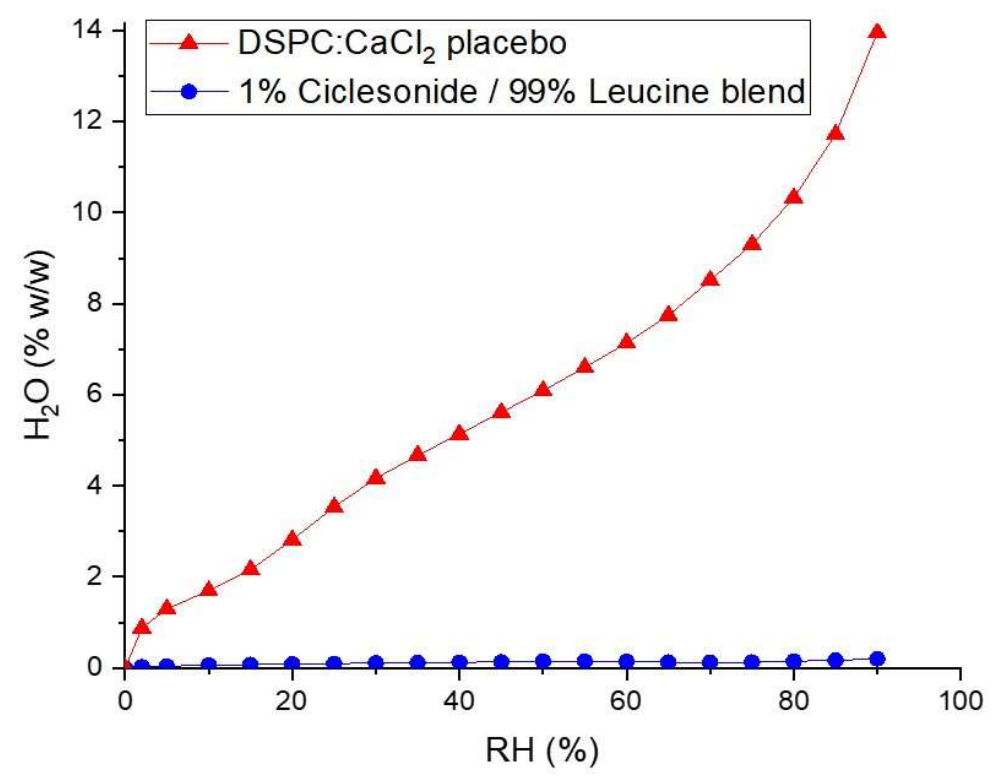

Fig. 5: Moisture sorption isotherm $\left(25^{\circ} \mathrm{C}\right)$ of $1 \% \mathrm{w} / \mathrm{w} \mathrm{CPI}$ in comparison with that of the standard PulmoSphere excipients comprising a 2:1 molar ratio of DSPC to calcium chloride.

\subsection{Aerosol Performance of Ciclesonide Powder for Inhalation}

Aerosol performance metrics for the CPI drug product are presented in Table 2.

Table 2. Aerosol performance metrics for CPI

\begin{tabular}{|c|c|c|}
\hline Metric & Method & Mean \pm SD \\
\hline Emitted dose $(\% \mathrm{ND})^{\text {a }}$ & DUSA / RP-HPLC & $94.0 \pm 0.7$ \\
\hline Fine particle fraction $<5 \mu \mathrm{m}(\% \mathrm{ED}){ }^{\mathrm{b}}$ & NGI / RP-HPLC & 96.8 \\
\hline Fine particle fraction S4-F (\% ED) ${ }^{b}$ & NGI / RP-HPLC & 94.5 \\
\hline Mass median aerodynamic diameter $(\mu \mathrm{m})^{b}$ & NGI / RP-HPLC & 1.66 \\
\hline Geometric standard deviation ${ }^{b}$ & NGI / RP-HPLC & 1.57 \\
\hline Mass median impaction parameter $\left(\mu \mathrm{m}^{2} \mathrm{~L} / \mathrm{min}\right)^{b}$ & NGI / RP-HPLC & 115.8 \\
\hline Total lung dose $(\% \mathrm{ED})^{\text {a }}$ & $\begin{array}{l}\text { Alberta idealized throat AIT } \\
\text { / RP-HPLC }\end{array}$ & 93.0 \\
\hline Total lung dose $(\% \mathrm{ED})^{\mathrm{a}}$ & $\begin{array}{l}\text { Idealized child throat ICT / } \\
\text { RP-HPLC }\end{array}$ & 86.5 \\
\hline$Q$ index $(\%)^{a}$ & ICT / RP-HPLC & -3.9 \\
\hline TLD 75\% RH / TLD 40\% $\mathrm{RH}^{\mathrm{b}}$ & ICT / RP-HPLC & 0.99 \\
\hline
\end{tabular}

${ }^{\mathrm{a}} \Delta \mathrm{P}=2 \mathrm{kPa}, \mathrm{V}=4 \mathrm{~L}\left(\right.$ AOS DPI); ${ }^{\mathrm{b}} \Delta \mathrm{P}=4 \mathrm{kPa}, \mathrm{V}=4 \mathrm{~L}($ AOS DPI)

The emitted dose with the high resistance AOS DPI at a pressure drop of $2 \mathrm{kPa}(Q=$ $27.7 \mathrm{~L} \mathrm{~min}^{-1}$ ) was $94.0 \pm 0.7 \%$. Hence, despite the fine size of the low density, rugous carrier particles, the powder formulation fluidizes and empties from the capsule and device with high efficiency.

The APSD of CPI was assessed in an NGI at a pressure drop of $4 \mathrm{kPa}(Q=39.2 \mathrm{~L} \mathrm{~min}$ $\left.{ }^{1}\right)$. The MMAD was $1.66 \mu \mathrm{m}$ with a GSD of 1.57. The large particle fraction, comprising ciclesonide deposition within the induction port, stage 1 , and stage 2 , was only $2.3 \%$, leading to a fine particle fraction less than $5 \mu \mathrm{m}\left(\mathrm{FPF}_{<5 \mu \mathrm{m}}\right)$ of $96.8 \%$. The bulk of the deposition 
in the NGI was concentrated on stages 4 to 6 , with limited deposition (4.4\%) on stage 7 and MOC.

Given that each stage within the NGI represents a specific $d_{a}^{2} Q$ cutoff, it is instructive to characterize the particle distribution within the NGI based on stage groupings. The mass median impaction parameter (MMIP) for drug particles deposited within the NGI is $115.8 \mu \mathrm{m}^{2} \mathrm{~L} / \mathrm{min}$ (Table 2). It is important to note that the calculated MMAD and MMIP values comprise more than $98 \%$ of the emitted dose of drug. This contrasts with standard LB and SPH particles where only the fine mode of the bimodal distribution (comprising just $10-50 \%$ of the drug) is assessed in the impactor. Under this circumstance, the MMIP value for CPI is comparable to the $d_{a}^{2} Q$ values detailed in Fig. 1 and Fig. 3.

\subsection{Total Lung Dose of CPI in Idealized Anatomical Throat Models}

The TLD was determined in both adult (Adult Idealized Throat, AIT) and pediatric (Idealized Child Throat, ICT) models, with mean values at a $2 \mathrm{kPa}$ pressure drop of $93.0 \%$ and $86.5 \%$ of the ED, respectively (Table 2, Fig. 6). These results are consistent with the results observed in the NGI, and deposition predictions based on the measured $\mathrm{MMIP} / d_{a}^{2} Q$ and Equations 3 and 4.

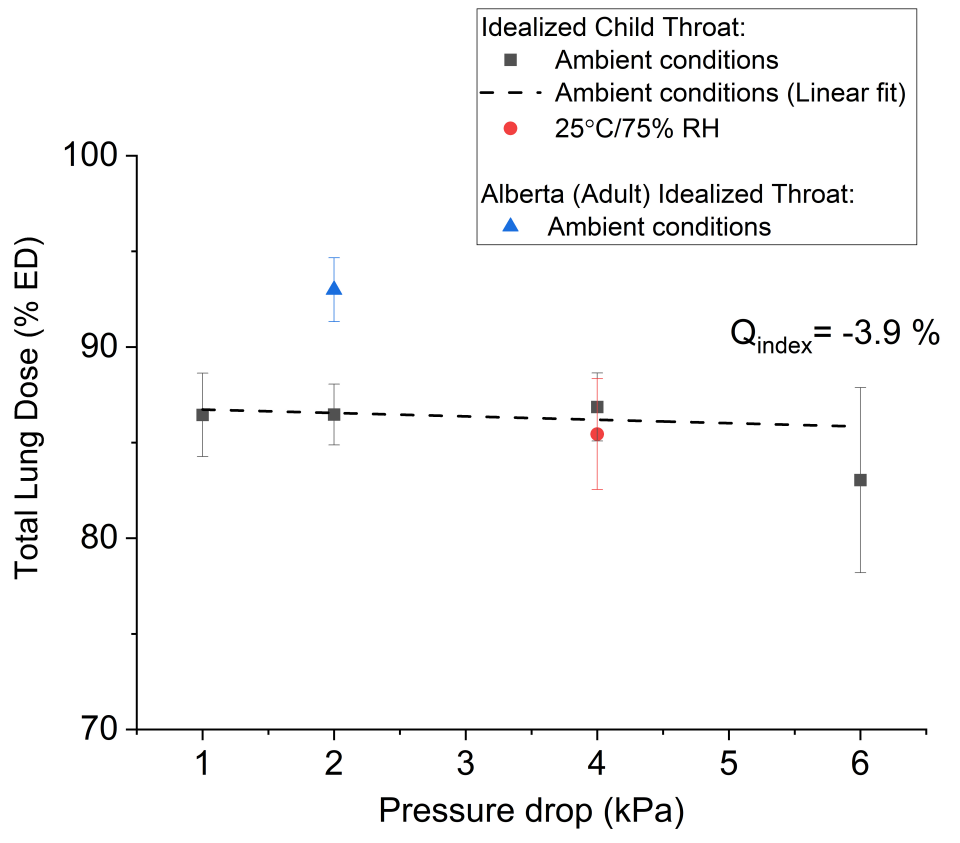

Fig. 6: TLD measured in anatomical throat models as a function of pressure drop and variations in relative humidity

The dependence of the TLD with variations in pressure drop/flow rate was assessed in the ICT model at pressure drops of 1, 2, 4, and $6 \mathrm{kPa}$ (Fig. 6). This corresponds to flow rates ranging from 19.6 to $48.0 \mathrm{~L} \mathrm{~min}^{-1}$. Healthy seven-year-old children achieve a maximum inspiratory pressure (MIP) of about $5 \mathrm{kPa}$ [50]. Subjects typically inhale at only 40 $80 \%$ of their MIP values when using DPIs [50]. This corresponds to pressure drops between about 2 and $4 \mathrm{kPa}$ in children. Indeed, most children ages six and above exceed a pressure drop of $\sim 1 \mathrm{kPa}$ when using passive DPIs [51-54]. This is especially true for children using higher resistance DPIs, as subjects tend to provide greater inspiratory effort when using a higher resistance device [55-59]. 
The flow rate dependence is expressed in terms of the $Q$ index, a metric that assesses flow rate dependence in terms of the normalized difference in TLD at pressure drops between $1 \mathrm{kPa}$ and $6 \mathrm{kPa}$ [59]. The measured value of $-3.9 \%$ is indicative of drug delivery that is largely independent of inspiratory flow rate.

Aerosol performance was also not impacted by increases in relative humidity, as the TLD measured at 75\% RH in an environmental chamber was equivalent to that measured at ambient room temperature $(20-40 \% \mathrm{RH})$. This is not surprising given the highly crystalline and hydrophobic nature of the drug and carrier, as illustrated by the very low moisture sorption characteristics detailed in Fig. 5.

\section{Discussion}

Leucine is a hydrophobic amino acid that is being utilized as a shell-forming excipient in carrier-free spray-dried particles for inhalation [47,60-62]. The presence of leucine or its tripeptide trileucine on the particle surface improves powder dispersibility by lowering the particle density and the radius of curvature at interparticle contact points [47]. One benefit of leucine and trileucine is that the shell they form in engineered core-shell particles provides a protective barrier against the detrimental effects of elevated humidity, reducing the magnitude of the instantaneous drop in aerosol performance that is often observed for amorphous solids due to increased capillary forces between particles [63-68].

In this study, low density spray-dried microparticles of neat leucine are used as carrier particles in adhesive mixtures. These carrier particles are 25 to 100 times smaller geometrically, and owing to their low particle density, up to 500 times smaller aerodynamically than coarse lactose carrier particles. We use flash nanoprecipitation into a nonsolvent to load the nanoparticles of drug onto circulating carrier particles. The nonsolvent is then removed, leaving behind the carrier-based dry powder. The environmental robustness observed with carrier-free particles comprising leucine is also noted in these 'nanoleucine' carrier formulations. The goal of achieving particles with a $d_{a}$ of $\sim 2.0 \mu \mathrm{m}$ and a $d_{a}^{2} Q$ of $\sim 100 \mu \mathrm{m}^{2} \mathrm{~L} \mathrm{~min}^{-1}$ was met.

Despite their small size, these blends are easily fluidized and dispersed with a passive DPI. Based on in vitro aerosol performance metrics, the formulation is expected to largely bypass deposition in the URT and deliver high percentages of the nominal dose to the large and small airways. The reduction in URT deposition and potential reductions in nominal dose are expected to decrease local adverse events (e.g., cough, throat irritation, opportunistic infections, dysphonia, dyspnea, bronchospasm), to decrease systemic adverse events particularly for drugs with oral bioavailability, and to reduce variability in lung delivery by reducing variability associated with oropharyngeal filtering of particles and dependence on inspiratory flow rate.

\subsection{Comparison of CPI to marketed ICS formulations}

To put the aerosol performance results observed with CPI in context, Fig. 7, Fig. 8, and Fig. 9 and Table 3 compare these results with results obtained for marketed ICS products.

Fig. 7 illustrates the improved lung targeting observed for CPI in adults relative to various marketed ICS formulations [59,69-72]. The plot leverages data from gamma scintigraphy and anatomical throat models. The results are expressed in terms of the ratio of LRT deposition (i.e., the TLD) to URT deposition. In the AIT model, the TLD/URT ratio for CPI is 13.3. This is more than five-fold greater than is achieved with the best marketed ICS product (i.e., budesonide administered with the high efficiency Respimat@ soft mist inhaler). Lung targeting with CPI is improved 55-fold relative to Advair® Diskus ${ }^{\circledR}$. 


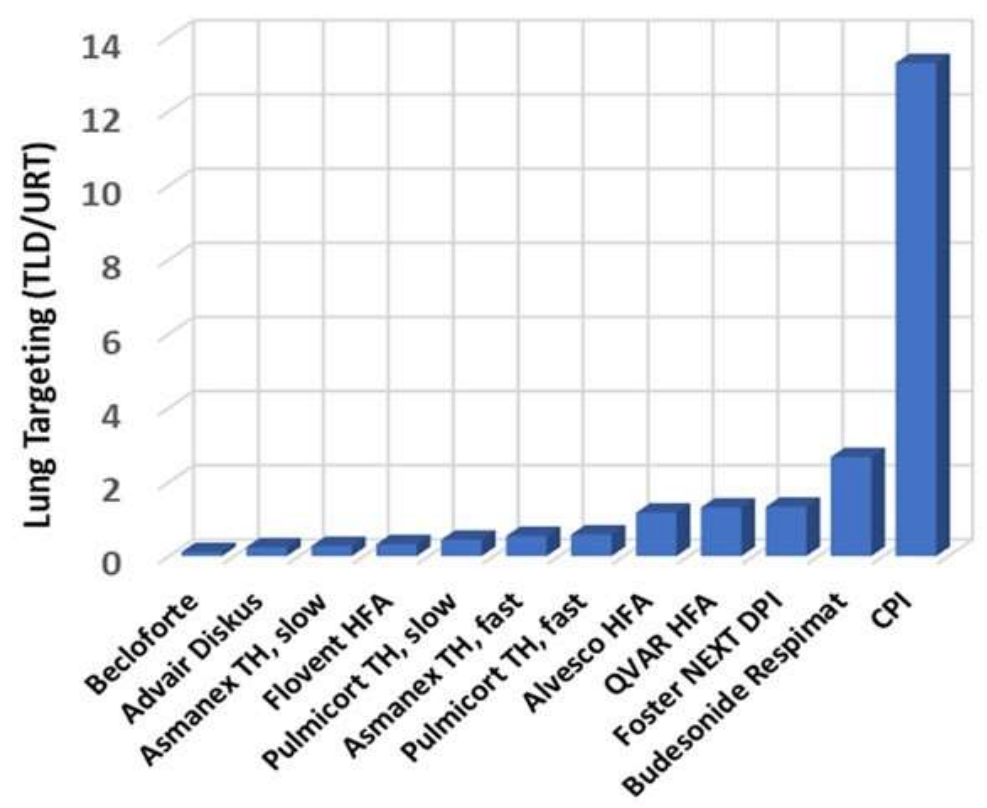

Fig. 7: Lung targeting observed for CPI relative to various ICS formulations [59,69-72]

\subsection{Regional deposition in the respiratory tract}

The transition from chlorofluorocarbon to hydrofluoroalkane propellants led to the development of solution-based pMDIs comprising extrafine ICS particles. Leach et al. demonstrated that $55-60 \%$ of the ex-actuator dose of an HFA solution formulation of BDP (QVAR, MMAD $=1.1 \mu \mathrm{m}$ ) was deposited in the lungs [73]. This was an astounding increase in TLD relative to the marketed CFC-BDP formulation at the time, where a $4-7 \%$ TLD was observed for fine particles with an MMAD of $3.5 \mu \mathrm{m}$. The extrafine QVAR formulation also deposited more than $30 \%$ of the ex-actuator dose in the peripheral lungs versus less than $3 \%$ for the CFC-BDP product [73].

Nonetheless it is important to point out that a formulation of extrafine particles is not a requirement for achieving high TLD and effective peripheral lung delivery of inhaled corticosteroids. This is illustrated in Fig. 8 in a comparison of Flovent HFA (fine particle pMDI), QVAR (extrafine particle pMDI), and a carrier-free PulmoSphere dry powder formulation comprising fine spray-dried particles of budesonide [70,74]. Comparing the two pMDI formulations supports the conclusion that finer particles (MMAD of 0.7 versus 2.0 $\mu \mathrm{m}$ ) leads to greater TLD ( $38 \%$ versus $18 \%$ of the nominal dose), increased peripheral lung delivery ( $23 \%$ versus $10 \%)$, and an increase in the ratio of peripheral to central lung delivery, $\mathrm{P} / \mathrm{C}$ (1.53 versus 1.25$)$.

The impact of aerodynamic diameter on regional deposition differs when a dry powder formulation that more effectively bypasses URT deposition is considered. Despite having an MMAD that is five times larger than that of QVAR, the TLD of the PulmoSphere DPI is increased from $38 \%$ to $58 \%$ and peripheral deposition is increased from $23 \%$ to $32 \%$ of the nominal dose. This is due to a significant decrease in the fraction of particles not sized in the impactor, i.e., those that are lost in the device and URT. Device and throat deposition is $59 \%$ of the nominal dose for QVAR versus $42 \%$ for the PulmoSphere DPI. For the extrafine CPI formulation in the present study, this fraction is markedly reduced to just $13 \%$ (AIT data).

While particle size is clearly important in achieving effective delivery to the lung periphery, developing formulations that reduce the large losses in the device and URT can 
be more impactful. Achieving improved lung delivery with larger sized particles may also reduce alveolar delivery and the probability of particle exhalation, as illustrated in Fig. 1c.

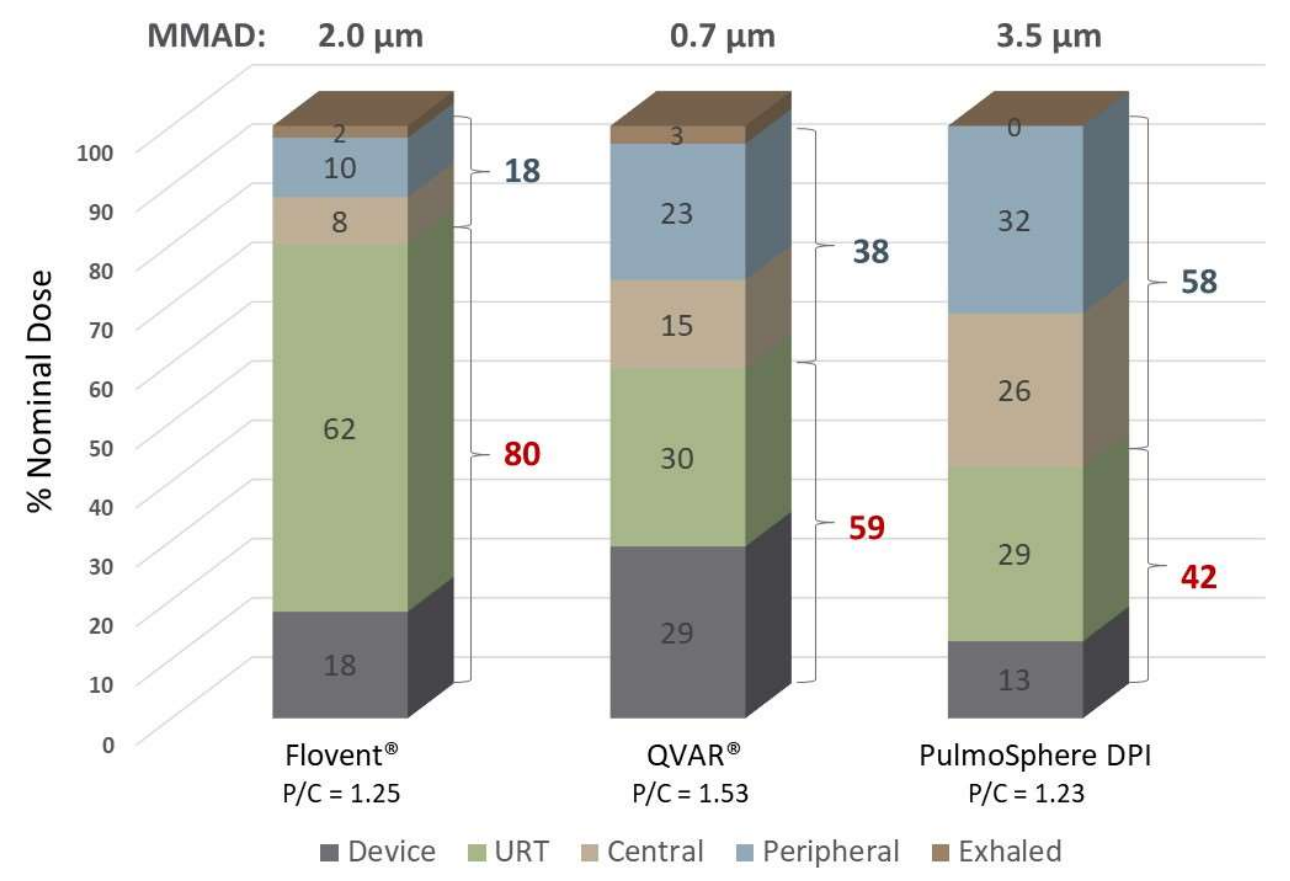

Fig. 8: Comparison of regional deposition in the respiratory tract as determined by gamma scintigraphy for various ICS formulations $[70,74]$.

The resistance of the device is another factor of critical importance in maximizing the TLD and peripheral lung delivery with DPIs. As discussed, inertial impaction is proportional to the impaction parameter, $d_{a}^{2} Q$. Subjects using higher resistance DPIs will inhale at lower flow rates, thereby decreasing inertial impaction. Given that inhaled flow rates with DPIs may vary from $\sim 15 \mathrm{~L} \mathrm{~min}^{-1}$ to $\sim 120 \mathrm{~L} \mathrm{~min}^{-1}$, the impact of device resistance on particle deposition can be significant. Additional work is needed, however, to establish the link between the impaction parameter, regional deposition within the lungs, and efficacy.

\subsection{Small airways delivery}

Fig. 9 and Table 3 compare the pattern of stage deposition of CPI in an NGI with five marketed products comprising inhaled corticosteroids [37,69-71,75]. Each class of formulation (e.g., DPI formulations comprising fine particles, extrafine solution pMDIs and DPIs, and CPI) exhibit characteristic 'fingerprints' in terms of their APSD. The top row of Fig. 9 compares CPI with two market-leading DPI products utilizing traditional dry powder formulation technologies. Asmanex ${ }^{\circledR}$ Twisthaler ${ }^{\circledR}$ contains spheronized particles of mometasone furoate, while Flovent ${ }^{\circledR}$ Diskus ${ }^{\circledR}$ contains a blend of fluticasone propionate with coarse lactose carrier particles $[37,75]$. Both formulations exhibit a bimodal APSD with most of the dose $(\sim 80 \%)$ deposited in the non-respirable 'large particle fraction'. Deposition in this stage grouping is about 40-fold higher than is observed for CPI. Deposition in the 'airways fraction' on stages 3 to 5 is about 4 to 5 -fold lower than CPI. Deposition on stages 4 and 5, a metric for small airways delivery, was about 7 to 8-fold lower than CPI. In essence, the coarse mode of the Asmanex and Flovent products has been shifted to particles of a respirable size in CPI. Equivalent fine particle deposition in the airways fraction would result in $\sim 200$-fold decreases in deposition in the large particle fraction. 

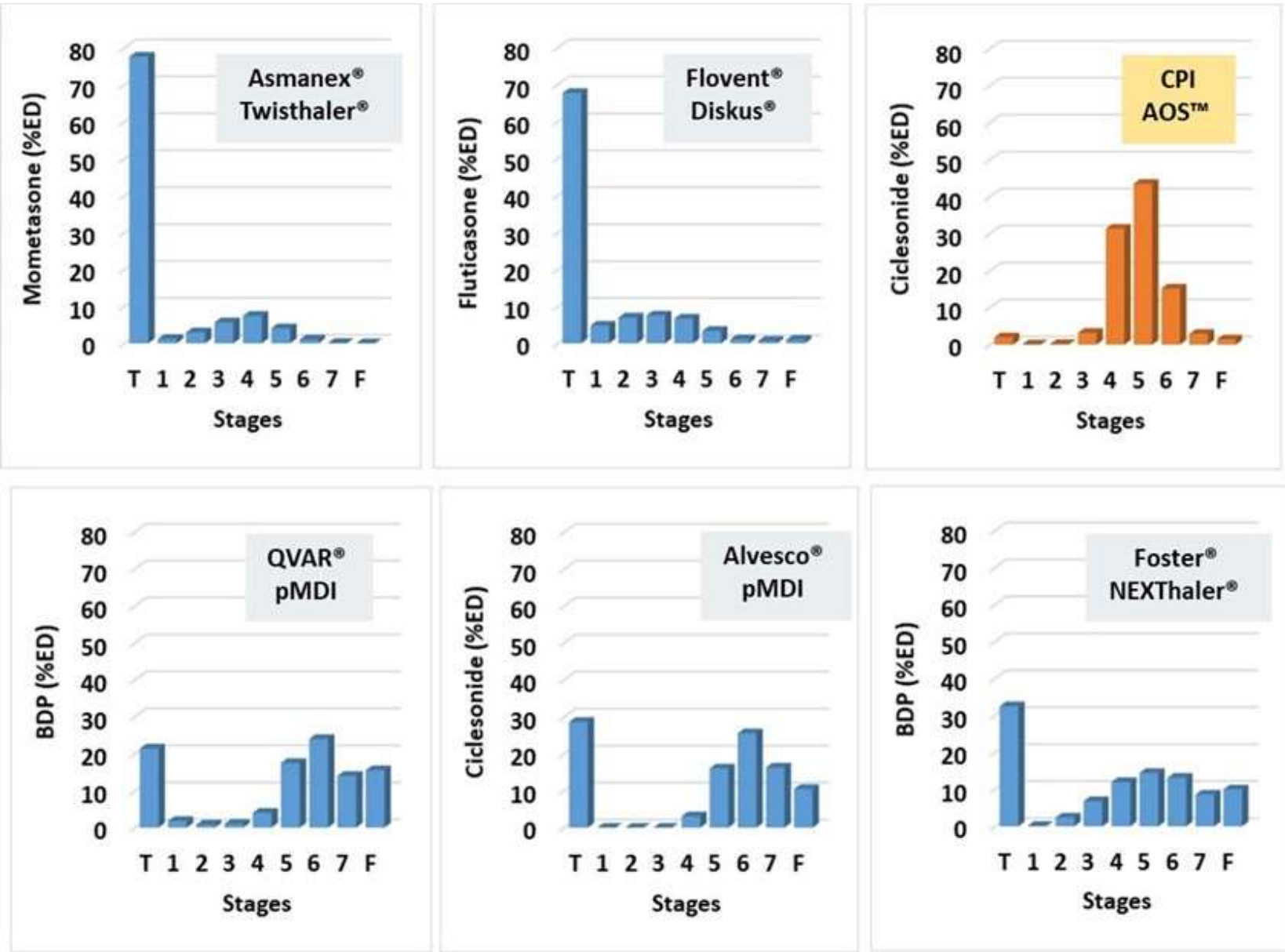

Fig. 9. Aerodynamic particle size distributions of inhaled corticosteroid formulations $[37,69,70,75]$

Table 3. Comparison of the stage distributions of various ICS formulations in an NGI $[37,69,70,75]$

\begin{tabular}{|c|c|c|c|c|c|c|c|}
\hline Aerosol Metric & $\begin{array}{c}\text { Mean } \\
\mathrm{d}_{\mathrm{a}}^{2} \mathrm{Q} \text { Cutoff } \\
\left(\mu \mathrm{m}^{2} \mathrm{~L} \mathrm{~min}^{-1}\right)\end{array}$ & $\begin{array}{c}\text { Asmanex } \\
\text { Twisthaler } \\
(\% E D) \\
\end{array}$ & $\begin{array}{l}\text { Flovent } \\
\text { Diskus } \\
\text { (\%ED) }\end{array}$ & $\begin{array}{c}\text { Alvesco } \\
\text { pMDI } \\
(\% E D) \\
\end{array}$ & $\begin{array}{l}\text { QVAR } \\
\text { pMDI } \\
(\% E D)\end{array}$ & $\begin{array}{c}\text { Foster } \\
\text { Nexthaler } \\
(\% E D) \\
\end{array}$ & $\begin{array}{c}\text { CPI AOS } \\
(\% E D)\end{array}$ \\
\hline Stage Grouping (T-S2) & $>1176$ & 81.7 & 79.6 & 28.6 & 24.0 & 35.0 & 2.3 \\
\hline Stage Grouping (S3-S5) & $56-1176$ & 16.6 & 18.3 & 19.2 & 22.5 & 33.3 & 78.1 \\
\hline Stage Grouping (S4-S5) & $56-467$ & 10.9 & 9.0 & 19.2 & 21.5 & 26.5 & 74.9 \\
\hline Stage Grouping (S6-F) & $<56$ & 2.7 & 1.2 & 52.2 & 53.5 & 31.8 & 19.6 \\
\hline Stage Grouping (S7-F) & $<21$ & 1.7 & 0.1 & 26.7 & 29.5 & 18.6 & 4.4 \\
\hline MMAD $(\mu \mathrm{m})$ & --- & 2.6 & 2.8 & 1.0 & 0.6 & 1.2 & 1.7 \\
\hline $\operatorname{MMIP}\left(\mu \mathrm{m}^{2} \mathrm{~L} \mathrm{~min}^{-1}\right)$ & --- & 394.8 & 704.2 & 29.0 & 30.9 & 61.8 & 115.8 \\
\hline Drug APSD & --- & Fine & Fine & Extrafine & Extrafine & Extrafine & Extrafine \\
\hline
\end{tabular}


The bottom row of products in Fig. 9 is made up of formulations comprising extrafine drug particles with MMAD values of $\sim 1 \mu \mathrm{m}$. These include two solution pMDIs (QVAR®) and Alvesco®) and a dry powder formulation (Foster $®$ Nexthaler $\left.{ }^{\circledR}\right)$ [69-71,75]. QVAR and Foster Nexthaler deliver beclomethasone dipropionate, while Alvesco delivers ciclesonide. These three formulations also exhibit bimodal APSDs with between $24 \%$ and $35 \%$ deposition in the 'large particle fraction' (coarse mode). Although not pictured, these formulations also exhibit higher deposition in the device (e.g., $29 \%$ for QVAR, 20\% for Alvesco, 12-17\% for Foster Nexthaler, versus only 6\% for CPI) [69-71,75]. A large percentage of their dose (32-54\%) deposits in the 'very fine particle fraction' on stage 6 to MOC versus $19.6 \%$ for CPI. These formulations deposit a modest amount of their dose (19-33\%) on stages 3 and 5 versus $78 \%$ for CPI. Deposition in the small airways fraction was 19-27\% vs. $75 \%$ for CPI. Hence, the dry powder CPI formulation may improve targeting to the large and small airways relative to both fine and extrafine ICS formulations, while potentially reducing unwanted extrathoracic and alveolar deposition. The improved targeting to the airways should enable significant reductions in nominal dose (i.e., steroid sparing), a feature of importance to all patients, especially pediatric subjects.

\subsection{Minimum flow rate}

DPIs are often classified in terms of the minimum flow rate that achieves acceptable powder dispersion and efficacy in vivo [76-78].

Dispersion of the drug from the carrier or spheronized particle agglomerate depends critically on the pressure drop patients achieve through their dry powder inhaler during inhalation. Pediatric, geriatric, and female patients have reduced muscle strength, and sometimes may be unable to generate the inspiratory pressures needed to achieve effective drug dispersion [76,78]. Mahler suggests that a flow rate of $60 \mathrm{~L} \mathrm{~min}^{-1}$ is required for effective delivery with a DPI in COPD patients [78]. This rule-of-thumb neglects the impact of variations in device resistance on the flow rates achievable in various DPIs. For this reason, it has been proposed that pressure drop is a better metric than flow rate for comparing DPIs [54]. It was further proposed that if patients can achieve a pressure drop of $\sim 1 \mathrm{kPa}$, that they can effectively use a dry powder inhaler [54]. For the drug-device combinations detailed herein, flow rates as low as $\sim 20 \mathrm{~L} \mathrm{~min}^{-1}(1 \mathrm{kPa})$ were demonstrated to effectively fluidize and disperse CPI. Indeed spray-dried porous particles with high delivery efficiency have demonstrated lung delivery that is independent of pressure drop down to pressure drops as low as $0.2 \mathrm{kPa}[7,48]$. The 'flow rate' limitations described in the literature for DPIs are more of a reflection of the limitations of LB and SPH formulations rather than an inherent limitation of DPIs.

\section{Conclusions}

- $\quad$ Adhesive mixtures comprising extrafine ciclesonide crystals and crystalline nanoleucine carrier particles achieve TLD values that are $93 \%$ and $87 \%$ of the ED in adult and child anatomical throat models, respectively.

- The TLD measured in the throat models was independent of flow rate and relative humidity.

- In an NGI, deposition of CPI in the 'large particle fraction' comprising the induction port, stage 1 and stage 2 was just $2.3 \%$ of the emitted dose. In the 'airways fraction' comprising stages 3 through stage 5, deposition was $78.1 \%$. In the 'very fine fraction' comprising stages 6 to MOC, deposition was 19.6\%.

- Lung targeting, expressed as the ratio of the TLD/URT deposition was significantly greater than current marketed ICS therapeutics.

- The nanoleucine carrier technology represents an alternative to traditional lactose blends and solution pMDIs, with improved ability to target drug to the large and small airways in the lungs, while minimizing extrathoracic and alveolar delivery. 


\section{Patents}

The material presented in this manuscript is the subject of a pending PCT patent application PCT/US2020/036944 submitted 10 Jun 2020. The application was published as: Miller, D.P., Tarara, T.E., Weers, J.G. Carrier-based formulations and related methods. WO2020251983A1 on 17 Dec 2020.

Author Contributions: Conceptualization, D.M., T.T., and J.W.; methodology, D.M., T.T., J.W.; formal analysis, D.M., T.T., J.W.; investigation, D.M., T.T..; resources, J.W.; data curation, D.M., T.T., J.W..; writing -J.W., D.M., T.T.; writing - review and editing, J.W., D.M.; visualization, D.M., T.T., J.W.; supervision, J.W.; project administration, J.W..; funding acquisition, J.W., D.M. All authors have read and agreed to the published version of the manuscript.

Funding: This research was funded by the Eunice Kennedy Shriver National Institute of Child Health \& Human Development of the National Institute of Health under Award Number R43HD100216. The content is solely the responsibility of the authors and does not necessarily represent the official views of the National Institutes of Health.

Acknowledgments: The authors would like to recognize the contribution of Dr. Erwin Gelfand who provided guidance on the clinical utility of the work presented herein.

Conflicts of Interest: At the time of conduct of this work the authors were employees of Respira Therapeutics, receiving monetary and other forms of compensation. The authors declare no additional conflicts of interest. The funders had no role in the design of the study; in the collection, analyses, or interpretation of data; in the writing of the manuscript, or in the decision to publish the results.

\section{Abbreviations}

The following abbreviations are used in this manuscript.

$\begin{array}{ll}\text { AIT } & \text { Alberta idealized throat } \\ \text { AOS }{ }^{\circledR} \text { DPI } & \text { Axial oscillating sphere dry powder inhaler } \\ \text { APSD } & \text { Aerodynamic particle size distribution } \\ \text { CIC } & \text { Ciclesonide } \\ \text { COPD } & \text { Chronic obstructive pulmonary disease } \\ \text { CPI } & \text { Ciclesonide powder for inhalation } \\ \text { CT } & \text { Computed tomography } \\ D & \text { Diameter of the airspace } \\ \text { Da } & \text { Median aerodynamic diameter for primary particles } \\ d_{a} & \text { Aerodynamic diameter } \\ d_{a}^{2} Q & \text { Impaction parameter } \\ d_{g} & \text { Geometric diameter } \\ d_{p} & \text { Particle diameter } \\ \text { DSPC } & \text { Distearoylphosphatidylcholine } \\ \text { DUSA } & \text { Dose unit sampling apparatus } \\ \text { DVS } & \text { Dynamic vapor sorption } \\ \text { ED } & \text { Emitted dose } \\ \text { FPF }<5 \mu \mathrm{m} & \text { Fine particle fraction less than } 5 \mu \text { m } \\ g & \text { Acceleration due to gravity } \\ \text { ICS } & \text { Inhaled corticosteroid } \\ \text { ICT } & \text { Idealized child throat } \\ \text { IP } & \text { Induction port } \\ \text { LEU } & \text { Leucine } \\ \text { LB } & \text { Lactose blend } \\ \text { LRT } & \text { Lower respiratory tract } \\ \text { MIP } & \text { Maximum inspiratory pressure } \\ \text { MMAD } & \text { Mass median aerodynamic diameter } \\ \text { MMIP } & \text { Mass median impaction parameter } \\ \text { MOC } & \text { Micro orifice collector } \\ & \end{array}$




$\begin{array}{ll}\text { ND } & \text { Nominal dose } \\ \text { NP } & \text { Nanoparticles } \\ \text { PFOB } & \text { Perfluorooctyl bromide, Perflubron USP } \\ \text { RH } & \text { Relative humidity } \\ \text { RP-HPLC } & \text { Reverse phase-High performance liquid chromatography } \\ \text { SPH } & \text { Spheronized particles } \\ \text { Stk } & \text { Stokes Number } \\ \text { TLD } & \text { Total lung dose } \\ \text { URT } & \text { Upper respiratory tract } \\ \text { USP } & \text { United States Pharmacopeia } \\ \text { UV } & \text { Ultraviolet } \\ X_{10} & \text { Diameter for which } 10 \% \text { of the particles have a smaller size } \\ X_{50} & \text { Diameter for which } 50 \% \text { of the particles have a smaller size } \\ X_{90} & \text { Diameter for which } 90 \% \text { of the particles have a smaller size } \\ \text { XRPD } & \text { X-ray powder diffraction } \\ \rho_{p} & \text { Particle density } \\ \rho_{t a p p e d} & \text { Tapped density } \\ \mu & \text { Dynamic viscosity } \\ u & \text { Linear velocity } \\ v & \text { Terminal settling velocity }\end{array}$




\section{References}

1. Darquenne, C. Deposition mechanisms. J. Aerosol Med. Pulm. Drug Deliv. 2020, 33, 181-185. https://doi.org/10.1089/jamp.2020.29029.cd.

2. Carr, T. F., Altisheh, R., Zitt, M. Small airways disease and severe asthma. World Allergy Organ. J. 2017, 10, 20. https://doi.org/10.1186/s40413-017-0153-4.

3. Usmani, O. S. Treating the small airways. Respiration 2012, 84, 441-453. https://doi.org/10.1159/000343629.

4. Keen, C., Olin, A. C., Wennergren, G., Gustafsson, P. Small airway function, exhaled NO and airway hyper-responsiveness in paediatric asthma. Respir. Med. 2011, 105, 1476-1484. https://doi.org/10.1016/j.rmed.2011.04.004.

5. Hamid, Q., Song, Y., Kotsimbos, T. C., Minshall, E., Bai, T. R., Hegele, R. G., Hogg, J. C. Inflammation of small airways in asthma. J. Allergy Clin. Immunol. 1997, 100, 44-51. https://doi.org/10.1016/S0091-6749(97)70193-3.

6. Lavorini, F., Pedersen, S. \& Usmani, O.S. Dilemmas, confusion, and misconceptions related to small airways directed therapy. Chest. 2017, 151, 1345-1355. https://doi.org/10.1016/j.chest.2016.07.035.

7. Weers, J.G., Son, Y.-J., Glusker, M., Haynes, A., Huang, D., Kadrichu, N., Le, J., Li, X, Malcolmson, R., Miller, D.P., Tarara, T.E., Ung, K., Clark, A. Idealhalers versus realhalers: is it possible to bypass deposition in the upper respiratory tract? J. Aerosol Med. Pulm. Drug Deliv. 2019, 32, 55-69. https://doi.org/10.1089/jamp.2018.1497.

8. Stahlhofen, W., Rudolf, G. \& James, A.C. Intercomparison of experimental regional deposition data. J. Aerosol Med. 1989, 2, 285308. http://doi.org/10.1089/jam.1989.2.285.

9. Borgström, L., Olsson, B., Thorsson, L. Degree of throat deposition can explain the variability in lung deposition of inhaled drugs. J. Aerosol Med. 2006, 19, 473-483. http://doi.org/10.1089/jam.2006.19.473.

10. Stapleton, K.W., Guentsch, E., Hoskinson, M.K., Finlay, W.H. On the suitability of the $\kappa-\varepsilon$ turbulence model for aerosol deposition in the mouth and throat: a comparison with experiments. J. Aerosol. Sci. 2000, 31, 739-749. https://doi.org/10.1016/S00218502(99)00547-9.

11. Grgic, B., Finlay, W.H., Heenan, A.F. Regional aerosol deposition and flow measurements in an idealized mouth and throat. J. Aerosol. Sci. 2004, 35, 21-32. https://doi.org/10.1016/S0021-8502(03)00387-2.

12. Golshahi, L., Noga, M.L., Finlay, W.H. Deposition of inhaled micrometer-sized particles in oropharyngeal airway replicas of children at constant flow rates. J. Aerosol Sci. 2012, 49, 21-31. https://doi.org/10.1016/j.jaerosci.2012.03.001.

13. Golshahi, L., Finlay, W.H. An idealized child throat that mimics average pediatric oropharyngeal deposition. Aerosol Sci. Technol. 2012, 46, i-iv. https://doi.org/10.1080/02786826.2012.667170.

14. Olsson, B., Borgström, L., Lundbäck, H., Svensson, M. Validation of a general in vitro approach for prediction of total lung deposition in healthy adults for pharmaceutical inhalation products. J. Aerosol Med. Pulm. Drug Deliv. 2013, 26, 355-369 (2013). https://doi.org/10.1089/jamp.2012.0986.

15. Delvadia, R.R., Longest, P.W., Byron, P.R. In vitro tests for aerosol deposition. I: Scaling a physical model of the upper airways to predict drug deposition variation in normal humans. J. Aerosol Med. Pulm. Drug Deliv. 2012, 25, 32-40. https://doi.org/10.1089/jamp.2011.0905.

16. Wei, X., Hindle, M., Kaviratna, A., Huynh, B.K., Delvadia, R.R., Sandell, D., Byron, P.R. In vitro tests of aerosol deposition. VI: Realistic testing with different mouth-throat models and in vitro-in vivo correlations for a dry powder inhaler, metered dose inhaler, and soft mist inhaler. J. Aerosol Med. Pulm. Drug Deliv. 2018, 31, 358-371. https://doi.org/10.1089/jamp.2018.1454.

17. Tavernini S., Church, T.K., Lewis, D.A., Noga, M., Martin, A.R., Finlay, W.H. Deposition of micrometer-sized particles in neonatal nasal airway replicas. Aerosol Sci. Tech. 2018, 52, 407-419. https://doi.org/10.1080/02786826.2017.1413489.

18. Delvadia, R.R., Hindle, M., Longest, P.W., Byron, P.R. In vitro tests for aerosol deposition. II: IVIVCs for different dry powder inhalers in normal adults. J. Aerosol Med. Pulm. Drug Del. 2012, 26, 138-144. https://doi.org/10.1089/jamp.2012.0975.

19. Delvadia, R.R., Longest, P.W., Byron, P.R. In vitro tests for aerosol deposition. III: Effect of inhaler insertion angle on aerosol deposition: Scaling a physical model of the upper airways to predict drug deposition variation in normal humans. J Aerosol Med Pulm Drug Deliv 2013, 26, 145-156. https://doi.org/10.1089/jamp.2012.0989.

20. Ruzycki, C.A., Golshahi, L., Vehring, R. \& Finlay, W.H. Comparison of in vitro deposition of pharmaceutical aerosols in an idealized child throat with in vivo deposition in the upper respiratory tract of children. Pharm. Res. 2014, 31, 1525-1535. https://doi.org/10.1007/s11095-013-1258-2.

21. Weers, J.G., Clark, A.R., Rao, N., Ung, K., Haynes, A., Khindri, S., Perry, S.A., Machineni, S., Colthorpe, P. In vitro-in vivo correlations observed with indacaterol-based formulations delivered with the Breezhaler. J. Aerosol Med. Pulm. Drug Deliv. 2015, 28, 268-280. https://doi.org/10.1089/jamp.2014.1178.

22. Haynes, A., Geller, D., Weers, J.G., Ament, B., Pavkov, R., Malcolmson, R., Debonnet, L., Mastoridis, P., Yadao, T., Heuerding S. Inhalation of tobramycin using simulated cystic fibrosis inhalation profiles. Pediatr. Pulmonol. 2016, 51, $1159-1167$. https://doi.org/10.1002/ppul.23451.

23. Zhang, Y., Gilbertson, K., Finlay, W.H. In vivo-in vitro comparison of deposition in three mouth-throat models with QVAR® and Turbuhaler ${ }^{\circledR}$ inhalers. J. Aerosol Med. 2007, 20, 227-235. http://doi.org/10.1089/jam.2007.0584.

24. Kaviratna, A., Tian, G., Liu, X., Delvadia, R., Lee, S., Guo, C. Evaluation of bio-relevant mouth-throat models for characterization of metered dose inhalers. AAPS PharmSciTech. 2019, 20, 130. https://doi.org/10.1208/s12249-019-1339-6. 
25. Zhou, Y., Sun, J., Cheng, Y.-S. Comparison of deposition in the USP and physical mouth-throat models with solid and liquid particles. J. Aerosol Med. Pulm. Drug Deliv. 2011, 24, 277-284. https://doi.org/10.1089/jamp.2011.0882.

26. Newman, S.P., Chan, H.-K. In vitro-in vivo correlations (IVIVCs) of deposition for drugs given by oral inhalation. Adv. Drug Deliv. Rev. 2020, 167, 135-147. https://doi.org/10.1016/j.addr.2020.06.023.

27. Usmani, O.S., Biddiscombe, M.F., Barnes, P.J. Regional lung deposition and bronchodilator response as a function of $\beta_{2}$-agonist particle size. Am. J. Respir. Crit. Care Med. 2005, 172, 1497-1504. https://doi.org/10.1164/rccm.200410-1414OC.

28. Hoppentocht, M., Hagedoorn P., Frijlink H.W., DeBoer, A.H. Technological and practical challenges of dry powder inhalers and formulations. Adv. Drug Deliv. Rev. 2014, 75, 18-31. https://doi.org/10.1016/j.addr.2014.04.004.

29. Ung, K.T., Rao, N., Weers, J.G., Huang, D., Chan, H.-K. Design of spray dried insulin microparticles to bypass deposition in the extrathoracic region and maximizing total lung dose. Int. J. Pharm. 2016, 511, 1070-1079. https://doi.org/10.1016/j.ijpharm.2016.07.073.

30. Chew, N.Y.K., Chan, H.K. Use of solid corrugated particles to enhance powder aerosol performance. Pharm. Res. 2001, 18, 15701577. https://doi.org/10.1023/A:1013082531394.

31. Vehring, R. Pharmaceutical particle engineering by spray drying. Pharm. Res. 2008, 25, 999-1022. https://doi.org/10.1007/s11095007-9475-1.

32. Weers, J.G., Miller, D.P. Formulation design of dry powders for inhalation. J. Pharm. Sci. 2015, 104, 3259-3288. https://doi.org/10.1002/jps.24574. https://doi.org/10.1002/jps.24574.

33. Trevino, L.A., Dellamary, L.A., Tarara, T.E., Weers, J.G., Ranney, H.M. Continuous fluorochemical microdispersions for the delivery of lipophilic pharmaceutical agents. U.S. Patent 5,667,809, 1997.

34. Ostwald, W. Z. Phys. Chem. 1901, 37, 385.

35. Lifshitz, I.M., Slezov, V., The kinetics of precipitation from supersaturated solid solution, J. Phys. Chem. Solids 1961, 19, 35.

36. Hartman, M., Tarara, T.E., Teung, P., Weers, J.G. Respirable agglomerates of porous particles. U.S. Patent 9,744,178, 2017.

37. Weers, J.G., Tarara, T., Teung, P., Walsh, K., Rao, N., Le, J., Haynes, A., Huang, D., Miller, D.P. Solving the particle adhesion paradox: Respirable agglomerates of micronized drugs and porous (microcarrier) particles. Proc. Respir. Drug Deliv. Europe 2015. 2015, 1, 177-185.

38. Vehring, R., Lechuga-Ballesteros, D., Joshi, V., Noga, B., Dwivedi, S. Cosuspensions of microcrystals and engineered microparticles for uniform and efficient delivery of respiratory therapeutics from pressurized metered dose inhalers. Langmuir 2012, 28,15015-15023. https://doi.org/10.1021/la302281n.

39. Weers, J., Lyons, S., Tarara, T., Miller, D.P., Molloy, L., Weers, A., Saavedra, K., Heller, D., Curtis, R. The AOS ${ }^{\mathrm{TM}}$ DPI. a capsulebased dry powder inhaler with four distinct dispersion elements. Proc. Respir. Drug Deliv. 2020, 2020, 2, 459-462.

40. Weers, J., Rao, N.; Kadrichu, N. Is aerodynamic diameter a good metric for understanding regional deposition? Proc. Respir. Drug Deliv. Europe 2019, 2019, 1, 59-66.

41. Weers, J.G. Regional deposition of particles within the respiratory tract should be linked to impaction parameter, not aerodynamic size. J. Aerosol Med. Pulm. Drug Deliv. 2018, 31, 116-118. https://doi.org/10.1089/jamp.2018.1452.

42. Dolovich, M.B.; Mitchell, J.D.; Roberts, D.L. Re: "Harmonizing the nomenclature for therapeutic aerosol particle size: a proposal" by Hillyer et al. (J. Aerosol Med. Pulm. Drug Deliv. 2018 [31(2):111-113; doi: 10.1089/jamp.2017.1396] J. Aerosol Med. Pulm. Drug Deliv. 2018, 31, 266-268. https://doi.org/10.1089/jamp.2018.1479.

43. Martin, A.R., Moore, C.P., Finlay, W.H. Models of deposition, pharmacokinetics, and intersubject variability in respiratory drug delivery. Exp. Opin. Drug Deliv. 2018, 15, 1175-1188. https://doi.org/10.1080/17425247.2018.1544616.

44. Dunbar, C., Hickey, A.J., Holzner, P. Dispersion and characterization of pharmaceutical dry powder aerosols. KONA, 1998, 16, 7-45. https://doi.org/10.14356/kona.1998007.

45. Leung, S.S.Y., Tang, P., Zhou, Q., Tong, Z., Leung, C., Decharaksa, J., Yang, R., Chan, H.-K. De-agglomeration effect of the US Pharmacopeia and Alberta throats on carrier-based powders in commercial inhalation products. AAPS J. 2015, 17, 1407-1416. https://doi.org/10.1208/s12248-015-9802-0.

46. Feth, M.P., Volz, J., Hess, U., Sturm, E., Hummel, R.P. Physicochemical, crystallographic, thermal, and spectroscopic behavior of crystalline and X-ray amorphous ciclesonide. J. Pharm. Sci. 2008, 97, 3765-3780. https://doi.org/10.1002/jps.21223.

47. Ordoubadi, M., Gregson, F.K.A., Wang, H., Nicholas, M., Gracin, S., Lechuga Ballesteros, D., Reid, J.P., Finlay, W.H., Vehring, R., 2020. On the particle formation of leucine in spray drying of inhalable microparticles. Int. J. Pharm. 2021, 592, 120102. https://doi.org/ 10.1016/j.ijpharm.2020.120102.

48. Weers, J.G., Tarara, T.E. The PulmoSphere ${ }^{\mathrm{TM}}$ platform for pulmonary drug delivery. Ther. Deliv. 2014, 8, 647-661. https://doi.org/10.4155/tde.14.3.

49. Weers, J.G., Miller, D.P., Tarara, T.E. Spray-dried PulmoSphere ${ }^{\mathrm{TM}}$ formulations for inhalation comprising crystalline drug particles. AAPS PharmSciTech 2019, 20, 103. https://doi.org/10.1208/s12249-018-1280-0.

50. Clark, A. R. The role of inspiratory pressures in determining the flow rates though dry powder inhalers: a review. Curr. Pharm. Des. 2015, 21, 3974-3983. https://doi.org/10.2174/1381612821666150820105800.

51. Pedersen, S. How to use a Rotahaler. Arch. Dis. Child. 1986, 61, 11-14.

52. Pedersen S., Hansen O.R., Fugelsang. G. Influence of inspiratory flow rate upon the effect of a Turbuhaler. Arch. Dis. Child. 1990, $65,308-310$. 
53. Bentur, L., Mansour, Y., Hamzani, Y., Beck, R., Elias, N., Amirav, I. Measurement of inspiratory flow in children with acute asthma. Pediatr. Pulmonol. 2004, 38, 304-307. https://doi.org/10.1002/ppul.20109.

54. Clark, A.R., Weers, J.G., Dhand, R. The confusing world of dry powder inhalers; It is all about inspiratory pressures, not inspiratory flow rates. J. Aerosol Med. Pulm. Drug Deliv. 2020, 33, 1-11. https://doi.org/10.1089/jamp.2019.1556.

55. De Koning, J.P., Van der Mark, T.W., Coenegracht, P.M.J., Tromp, T.F.J., Frijlink, H.W. Effect of an external resistance to airflow on the inspiratory flow curve. Int. J. Pharm. 2002, 234, 257-266. https://doi.org/10.1016/S0378-5173(01)00969-3.

56. Tiddens, H.A., Geller, D.E., Challoner, P., Speirs, R.J., Kesser, K.C., Overbeek, S.E., Humble, D., Shrewsbury, S.B., Standaert, T.A. Effect of dry powder inhaler resistance on the inspiratory flow rates and volumes of cystic fibrosis patients of six years and older. J. Aerosol Med. 2006, 19, 456-465. https://doi.org/10.1089.jam.2006.19.456.

57. Azouz, W., Chetcuti, P., Hosker, H.I.S., Saralaya, D., Stephenson, J., Chrystyn, H. The inhalation characteristics of patients when they use dry powder inhalers. J. Aerosol Med. Pulm. Drug. Deliv. 2015, 28, 35-42. https://doi.org/10.1089/jamp.2013.1119.

58. Sahay, S., Holy, R., Lyons, S., Parsley, E., Maurer, M., Weers, J. Impact of human behavior on inspiratory flow profiles in patients with pulmonary arterial hypertension using AOS ${ }^{\mathrm{TM}}$ dry powder inhaler device. Pulm. Circ. 2021, 11, 1-9. https://doi.org/10.1177/2045894020985345.

59. Weers, J.G., Clark, AR: The impact of inspiratory flow rate on drug delivery to the lungs with dry powder inhalers. Pharm. Res. 2017, 34, 507-528. https://doi.org/10.1007/s-11095-016-2050-x.

60. Boraey, M.A., Hoe, S., Sharif, H., Miller, D.P., Lechuga-Ballesteros, D., Vehring, R. Improvement of the dispersibility of spraydried budesonide powders using leucine in an ethanol-water co-solvent system. Powder Technol. 2013, 236, 171-178. https://doi.org/10.1016/j.powtec.2012.02.047.

61. Lechuga-Ballesteros, D., Charan, C., Stults, C.L.M., Stevenson, C.L., Miller, D.P., Vehring, R., Tep, V., Kuo, M.-C., 2008. Trileucine improves aerosol performance and stability of spray-dried powders for inhalation. J. Pharm. Sci., 2008, 97, $287-302$.

https://doi.org/10.1002/jps.21078.

62. Wang, Z., Wang, H., Vehring, R. Leucine enhances the dispersibility of trehalose-containing spray-dried powders on exposure to a high-humidity environment. Int. J. Pharm. 2021, 601, 120561. https://doi.org/10.1016/j.ijpharm.2021.120561.

63. Cui, Y., Zhang, X., Wang, W., Huang, Z., Zhao, Z., Wang, G., Cai, S., Jing, H., Huang, Y., Pan, X., Wu, C., 2018. Moisture-resistant co-spray-dried netilmicin with l-leucine as dry powder inhalation for the treatment of respiratory infections. Pharmaceutics 2018, 10, 252. https://doi.org/10.3390/pharmaceutics10040252.

64. Feng, A.L., Boraey, M.A., Gwin, M.A., Finlay, P.R., Kuehl, P.J., Vehring, R. Mechanistic models facilitate efficient development of leucine containing microparticles for pulmonary drug delivery. Int. J. Pharm. 2011, 409, 156-163.

https://doi.org/10.1016/j.ijpharm.2011.02.049.

65. Li, L., Leung, S.S.Y., Gengenbach, T., Yu, J., Gao, G., Tang, P., Zhou, Q., Chan, H.K. Investigation of L-leucine in reducing the moisture-induced deterioration of spray-dried salbutamol sulfate power for inhalation. Int. J. Pharm. 2017, 530, 30-39. https://doi.org/10.1016/j.ijpharm.2017.07.033.

66. Li, L., Sun, S., Parumasivam, T., Denman, J.A., Gengenbach, T., Tang, P., Mao, S., Chan, H.K., 2016. L-Leucine as an excipient against moisture on in vitro aerosolization performances of highly hygroscopic spray-dried powders. Eur. J. Pharm. Biopharm. 2016, 102, 132-141. https://doi.org/10.1016/j.ejpb.2016.02.010.

67. Shetty, N., Park, H., Zemlyanov, D., Mangal, S., Bhujbal, S., Zhou, Q. Influence of excipients on physical and aerosolization stability of spray dried high dose powder formulations for inhalation. Int. J. Pharm. 2018, 544, 222-234. https://doi. org/10.1016/j.ijpharm.2018.04.034.

68. Sibum, I., Hagedoorn, P., Kluitman, M.P.G., Kloezen, M., Frijlink, H.W., Grasmeijer, F. Dispersibility and storage stability optimization of high dose isoniazid dry powder inhalation formulations with L-leucine or trileucine. Pharmaceutics 2020, 12, 114. https://doi.org/10.3390/pharmaceutics12010024.

69. Newman, S., Salmon, A., Nave, R., Drollmann, A. High lung deposition of 99mTc-labeled ciclesonide administered via HFA-MDI to patients with asthma. Respir. Med. 2006, 100, 375-384. https://doi.org/10.1016/j.rmed.2005.09.027.

70. Leach, C.L., Kuehl, P.J., Chand, R., McDonald, J.D. Respiratory tract deposition of HFA-beclomethasone and HFA-fluticasone in asthmatic patients. J. Aerosol Med. Pulm. Drug Deliv. 2016, 29, 127-133. https://doi.org/10.1089/jamp.2014.1199.

71. Mariotti, F., Sergio, F., Acerbi, D., Meyer, T., Herpich, C. Lung deposition of the extra fine dry powder fixed combination beclomethasone dipropionate plus formoterol fumarate via the NEXT DPI ${ }^{\circ}$ in healthy subjects, asthmatic, and COPD patients. Eur. Respir. J. 2011, 38, p830.

72. Pitcairn, G., Reader, S., Pavia, D., Newman, S. Deposition of corticosteroid aerosol in the human lung by Respimat ${ }^{\circledR}$ Soft Mist ${ }^{\mathrm{TM}}$ inhaler compared to deposition by metered dose inhaler or by Turbuhaler ${ }^{\circledast}$ dry powder inhaler. J. Aerosol Med. 2005, 18, 264272. https://doi.org/10.1089/jam.2005.18.264.

73. Leach, C.L., Davidson, P.J., Boudreau, R.J. Improved airway targeting with the CFC-free HFA-beclomethasone metered-dose inhaler compared with CFC-beclomethasone. Eur. Respir. J. 1998, 12, 1346-1353. https://doi.org/10.1183/09031936.98.12061346.

74. Duddu, S.P., Sisk, S.A., Walter, Y.H., Tarara, T.E., Trimble, K.R., Clark, A.R., Eldon, M.A., Elton, R.C., Pickford, M., Hirst, P.H., Newman, S.P., Weers, J.G. Improved lung delivery from a passive dry powder inhaler using an engineered PulmoSphere powder. Pharm. Res. 2002, 19, 689-695. https://doi.org/10.1023/a:1015322616613. 
75. Buttini, F., Brambilla, G., Copelli, D., Sisti, V., Balducci, A.G., Bettini, R., Pasquali, I. Effect of flow rate on in vitro aerodynamic performance of Nexthaler ${ }^{\circledR}$ in comparison with Diskus ${ }^{\circledR}$ and Turbuhaler ${ }^{\circledR}$ dry powder inhalers. J. Aerosol Med. Pulm. Drug Deliv. 2016, 29, 167-178. https://doi.org/10.1089/jamp.2015.1220.

76. Laube, B.L., Janssens, H.M., de Jongh, F.H.C., et al. What the pulmonary specialist should know about the new inhalation therapies. Eur. Respir. J. 2011, 37, 1308-1331. https://doi.org/10.1183/09031936.00166410.

77. Haidl, P., Heindl, S., Siemon, K., Bernacka, M., Cloes, R.M. Inhalation device requirements for patients' inhalation maneuvers. Respir. Med. 2016, 118, 65-75. https://doi.org/10.1016/j.rmed.2016.07.013.

78. Mahler, D.A. Peak inspiratory flow rate as a criterion for dry powder inhaler use in chronic obstructive pulmonary disease. Ann. Am. Thorac. Soc. 2017, 14, 1103-1107. https://doi.org/10.1513/AnnalsATS.201702-156PS. 